\title{
Targeting mTOR and Glycolysis in HER2-Positive Breast Cancer
}

\author{
Ryan W. Holloway (1) and Paola A. Marignani *(D) \\ Department of Biochemistry \& Molecular Biology, Faculty of Medicine, Dalhousie University, \\ Halifax, NS B3H 4R2, Canada; rhollowa@dal.ca \\ * Correspondence: paola.marignani@dal.ca; Tel.: +1-902-494-6033
}

check for

updates

Citation: Holloway, R.W.; Marignani, P.A. Targeting mTOR and Glycolysis in HER2-Positive Breast Cancer. Cancers 2021, 13, 2922. https:// doi.org/10.3390/cancers13122922

Academic Editor: Zhixiang Wang

Received: 10 May 2021

Accepted: 10 June 2021

Published: 11 June 2021

Publisher's Note: MDPI stays neutral with regard to jurisdictional claims in published maps and institutional affiliations.

Copyright: (c) 2021 by the authors. Licensee MDPI, Basel, Switzerland. This article is an open access article distributed under the terms and conditions of the Creative Commons Attribution (CC BY) license (https:// creativecommons.org/licenses/by/ $4.0 /)$.
Simple Summary: About one third of all breast cancers are classified as HER2-positive due to high levels of the HER2 cell surface protein. Drugs that target HER2 have been mostly successful, but this type of cancer returns at a high frequency once treatment has been completed. The high levels of HER2 also cause elevated activation of mechanistic target of rapamycin (mTOR) and enhanced glucose metabolism, both of which support cancer growth. Based on this, drugs have been developed to block mTOR and tested in clinical studies alone or in combination with drugs that target HER2. These treatments are successful but have more toxic effects and a higher chance that the cancer will return. Using drugs that mimic glucose deprivation in HER2-positive breast cancer patients has not been tested; however, preclinical studies have shown HER2-positive breast tumors are reduced by combining drugs that mimic glucose deprivation with mTOR inhibitors.

Abstract: Up to one third of all breast cancers are classified as the aggressive HER2-positive subtype, which is associated with a higher risk of recurrence compared to HER2-negative breast cancers. The HER2 hyperactivity associated with this subtype drives tumor growth by up-regulation of mechanistic target of rapamycin (mTOR) pathway activity and a metabolic shift to glycolysis. Although inhibitors targeting the HER2 receptor have been successful in treating HER2-positive breast cancer, anti-HER2 therapy is associated with a high risk of recurrence and drug resistance due to stimulation of the PI3K-Akt-mTOR signaling pathway and glycolysis. Combination therapies against HER2 with inhibition of mTOR improve clinical outcomes compared to HER2 inhibition alone. Here, we review the role of the HER2 receptor, mTOR pathway, and glycolysis in HER2-positive breast cancer, along with signaling mechanisms and the efficacy of treatment strategies of HER2-positive breast cancer.

Keywords: mTOR; glycolysis; HER2-positive breast cancer; 2-deoxyglucose; trastuzumab; Herceptin; LKB1; tumor recurrence; rapalog; PI3K-Akt-mTOR signaling pathway; clinical diagnostics

\section{Introduction}

In women, the most diagnosed cancer and a leading cause of cancer-related deaths worldwide is breast cancer [1,2]. The highest incidence of breast cancer occurs in the United States and Western Europe, whereas the lowest incidence is found in Africa and Asia. Black American women have the highest mortality rates of breast cancer, and Korean women have the lowest mortality rates [2]. Although mortality rates due to breast cancer are declining in developed regions of the world, mortality rates are increasing in developing regions where limitations for early detection and awareness of symptoms are contributing factors [3-6]. The type of breast cancer is characterized by overexpression or absence of hormonal receptors: estrogen receptor-positive $(\mathrm{ER}+)$, progesterone-positive $(\mathrm{PR}+)$, human epidermal growth factor receptor 2-positive (HER2-positive), or the absence of ER/PR/HER2 (triple-negative). HER2-positive breast cancer constitutes 15-30\% of all breast tumors [7-9]. Based on the gene expression-based test PAM50 [10], HER2-positive breast cancers have been grouped into four intrinsic molecular subtypes: luminal A, luminal B, HER2-overexpressing or HER2-enriched (HER2-E), and basal-like. Of these subtypes, HER2-E constitutes about 50-60\% of all HER2-positive breast cancers [11-13]. 
HER2-positive breast tumors progress faster and more aggressively than most other breast tumors. Anti-HER2 therapies often lead to the development of chemoresistance (reviewed in [14]) and an elevated risk of recurrence that increases mortality rates [15] (reviewed in [16]). HER2-positive breast cancer is associated with hyperactivation of the mTOR pathway and a metabolic shift from aerobic respiration to glycolysis (Figure 1). As the mechanistic target of rapamycin (mTOR) pathway [17] and glycolysis [18] also contribute to supporting tumor recurrence and chemoresistance, these signaling pathways have become appealing targets for HER2-positive breast cancer therapy.

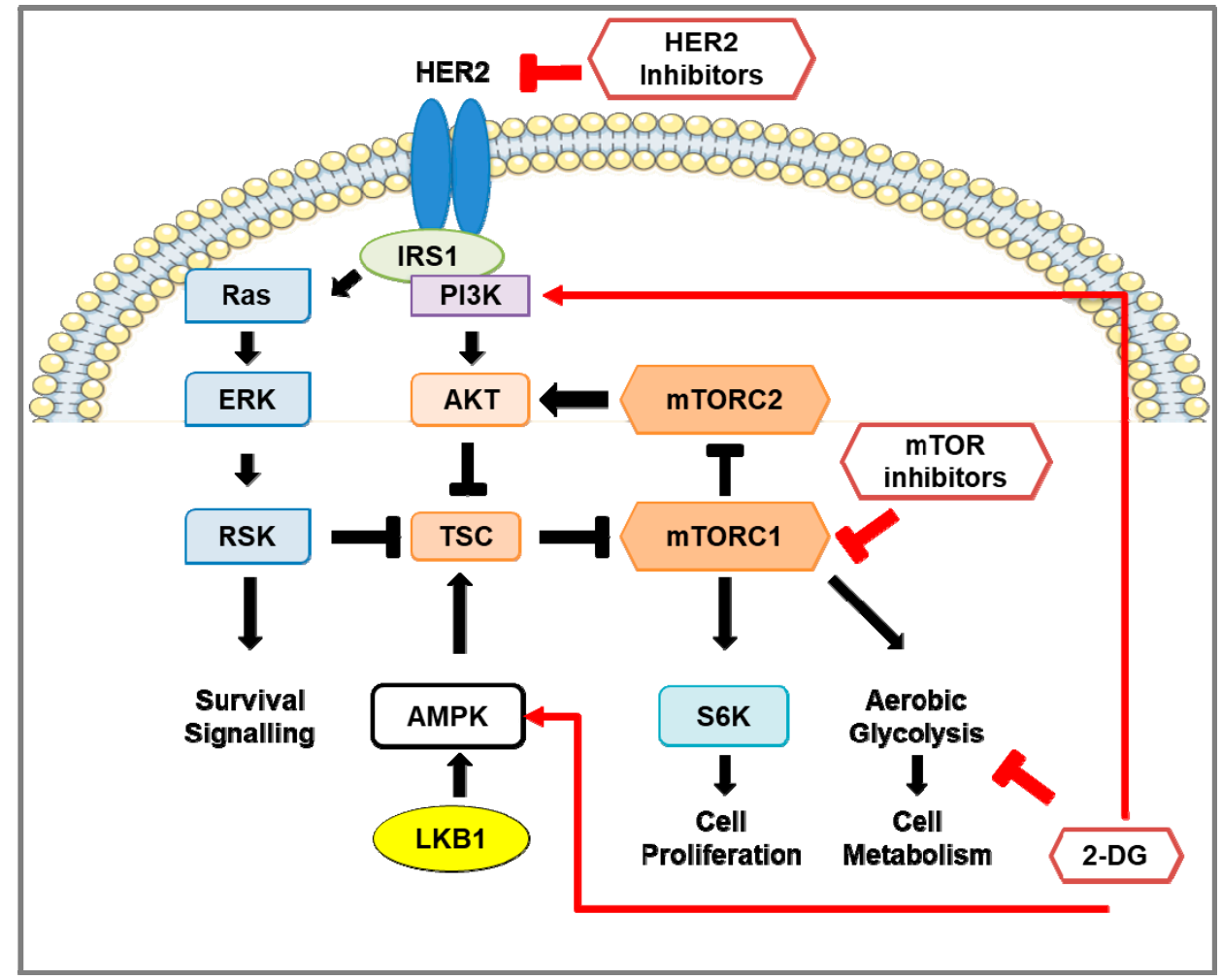

Figure 1. Pro-survival signaling in HER2-positive breast cancer and the effect of inhibition of HER2, mTOR, and glycolysis. Schematic representation of signaling pathways in HER2-positive breast cancer cells. HER2 and insulin receptor substrate (IRS) stimulates the RAS-ERK-RSK and AktmTOR pathways. Activation of mTOR signaling phosphorylates S6 kinase 1 (S6K) and eukaryotic initiation factor 4E-binding protein 1 (4E-BP1; not shown). The LKB1-AMP-dependent protein kinase alpha (AMPK) pathway negatively regulates $\mathrm{mTOR}$ signaling by activation of the mTOR inhibitors tuberous sclerosis complex-1 and -2 (TSC1/2). In HER2-positive breast cancer, HER2 inhibitors reduce the activity of the RAS-ERK-RSK and Akt-mTOR pathways and down-regulate glycolytic activity. However, re-activation of the mTOR pathway occurs, consequently enhancing glycolysis, pro-survival, and cell proliferation pathways. Treatment using mTOR inhibitors, such as rapamycin and rapalogs, in HER2-positive breast cancer prevents phosphorylation of S6K, inhibits cell proliferation, and reduces aerobic glycolysis through down-regulation of glycolytic enzymes. Prolonged inhibition of mTOR activates pro-survival pathways in a pERK-RSK- and Akt-dependent manner. The glucose analog 2-deoxy-D-glucose (2-DG) suppresses aerobic glycolysis, activates PI3K signaling, and promotes phosphorylation of AMPK on T172 to inhibit mTOR signaling.

\section{Neu/HER2 in Breast Cancer}

\subsection{Neu/HER2 Biology}

HER2 is a member of the epidermal growth factor (EGF) receptor family comprising EGFR/ErbB1, HER2/ErbB2, HER3/ErbB3, and HER4/ErbB4. EGF receptor family proteins encode for transmembrane receptors consisting of the extracellular ligand binding, lipophilic transmembrane, and cytoplasmic tyrosine kinase domains. Ligand binding to 
EGF receptors activates their hetero- or homodimerization whereby one EGF receptor will phosphorylate the other on a tyrosine, allowing cytoplasmic signaling complexes to bind to the EGFR dimer. This stimulates signal transduction cascades such as the PI3K-Akt-mTOR and MAPK pro-survival pathways [14,19] (reviewed in [20]). However, the proto-oncogene Neu/HER2 (HER2) has no known natural ligands [21]; thus, to elicit downstream signaling, HER2 preferentially dimerizes with EGF receptors that subsequently results in a more potent signaling response. Due to its role in activating signaling pathways that stimulate cell proliferation and survival, HER2 overexpression in breast tumor cells promotes tumor growth and increases the percentage of cells in $S$ phase, aneuploidy, and migration of cancer cells into the lymph nodes [22] (reviewed in [23]). Spontaneous homodimerization of HER2 is more prominent in HER2-positive breast cancer, shifting the balance of the EGR receptor dimers towards a greater ratio of homodimers [19,24]. Following dimerization, EGF receptors undergo endocytosis and are either recycled back to the cell surface or targeted for proteasomal degradation by ubiquitin ligase $\mathrm{Cbl}$ [25]. Dimerization stimulates EGFR/ErbB1 phosphorylation (Y1045) and recruitment of Cbl $[25,26]$; however, in heterodimers with ErbB2, Cbl recruitment is impeded. Although ErbB2 is phosphorylated (Y1112), Cbl recruitment is inefficient, and EGF receptors are recycled back to the cell surface [27].

\subsection{HER2 Inhibitors: Mechanisms of Action and Efficacy in Clinical Studies}

\subsubsection{Trastuzumab (Herceptin ${ }^{\circledR}$ )}

The humanized monoclonal antibody trastuzumab (Herceptin ${ }^{\circledR}$ ) was the first clinically used therapeutic agent to target HER2 for HER2-positive breast cancer (Figure 1) [28]. Trastuzumab binds to subdomain IV of the extracellular domain (ECD) of HER2; however, this does not inhibit HER2 dimerization or tyrosine kinase activity [29]. Rather, trastuzumab binding to HER2 induces antibody-dependent cellular cytotoxicity (ADCC) in which HER2-bound trastuzumab directs natural killer (NK) cells to destroy tumor cells [30]. Trastuzumab induction of ADCC in HER2-positive breast cancer cells was observed in allograph mouse models using tumor cells of Neu/HER2-expressing mice [30] and later observed in clinical trials $[27,31,32]$. Furthermore, HER2-specific monoclonal antibodies directed towards several epitopes were effective at reducing tumor growth in vivo [31] and enhanced the recruitment of $\mathrm{Cbl}$ to phosphorylated HER2 (Y1112), followed by its proteasomal degradation [31]. Phase II studies using trastuzumab in combination with other therapies showed a higher overall response rate (ORR) and median progression-free survival (PFS) than trastuzumab monotherapy (Table 1) [32-34]. Despite the success of trastuzumab therapy, recurrence-free survival is low (11-18\%) during the first 5 years of remission [35]. This relapse is common and frequently associated with brain metastases due to the inability of antibody-based treatments, such as trastuzumab, to traverse the blood-brain barrier [36]. Trastuzumab has been associated with injury to cardiac myocytes, although this effect was determined to be reversible. While the preliminary phase II trials observed minimal adverse cardiac effects [32,33], a phase III trial using patients, of whom many had previously received anthracycline therapy, had a high rate of cardiac dysfunction [37]. Evidence later indicated that the adverse cardiac effects were fairly low for trastuzumab monotherapy and prior anthracycline treatment (3-7\%) and anthracycline plus cyclophosphamide ( $8 \%$ ), but trastuzumab and anthracycline plus cyclophosphamide treatment showed a much higher incidence (27\%) [38]. HER2 activity was also found to play an essential role in regulating cardiac function and to prevent anthracycline cardiotoxicity $[39,40]$. 
Table 1. Clinical trials targeting HER2.

\begin{tabular}{|c|c|c|c|c|c|c|c|}
\hline Trea & ment & Trial Name & Patients & ORR & $\begin{array}{l}\text { Median PFS } \\
\text { (Months) }\end{array}$ & OS (Months) & REF \\
\hline \multirow{3}{*}{$\begin{array}{l}\text { Trastuzumab } \\
\text { (T) }\end{array}$} & Monotherapy & Phase II & 48 & $11.60 \%$ & 5.1 & $\mathrm{n} / \mathrm{a}$ & [32] \\
\hline & $\begin{array}{c}\mathrm{T}, \\
\text { chemotherapy }\end{array}$ & $\mathrm{n} / \mathrm{a}$ & 90 & $49.50 \%$ & 10 & $\begin{array}{c}16 \text { (from first } \\
\text { TZB treatment) }\end{array}$ & [34] \\
\hline & $\begin{array}{l}\mathrm{T} \text {, cisplatin, or } \\
\text { carboplatin }\end{array}$ & $\begin{array}{c}\text { UCLA- } \\
\text { ORN/BCIRG } \\
\text { Phase III }\end{array}$ & 62 & $58 \%$ & 12.7 & OS not reached & [33] \\
\hline \multirow{3}{*}{ Lapatinib (L) } & Monotherapy & $\begin{array}{c}\text { EGF20009 Phase } \\
\text { II }\end{array}$ & 136 & $24-31 \%$ & $\begin{array}{l}43 \% \text { of patients } \\
\text { at } 6 \text { months }\end{array}$ & OS not reached & [41] \\
\hline & $\begin{array}{l}\text { capecitabine } \\
\text { (cap) }\end{array}$ & $\begin{array}{c}\text { EGF100151 } \\
\text { (NCT00078572) }\end{array}$ & 399 & $13.90 \%$ & 4.4 & 15.3 & \multirow[t]{2}{*}{ [42-45] } \\
\hline & L, cap & Phase III & & $23.7 \%$ & 8.4 & 15.6 & \\
\hline \multirow{4}{*}{ Neratinib (N) } & $\begin{array}{l}\text { Monotherapy } \\
\text { (prior T } \\
\text { therapy) }\end{array}$ & \multirow{2}{*}{$\begin{array}{c}\text { NCT00300781 } \\
\text { Phase II }\end{array}$} & 66 & $24 \%$ & 22.3 & $\mathrm{n} / \mathrm{a}$ & \multirow[b]{2}{*}{ [46] } \\
\hline & $\begin{array}{l}\text { Monotherapy } \\
\text { (no prior } \\
\text { therapy) }\end{array}$ & & 70 & $56 \%$ & 39.6 & $\mathrm{n} / \mathrm{a}$ & \\
\hline & Monotherapy & $\begin{array}{c}\text { NCT00777101 } \\
\text { Phase II } \\
\end{array}$ & 117 & $29 \%$ & 4.5 & 19.7 & [47] \\
\hline & $\mathrm{N}$, cap & $\begin{array}{c}\text { NALA } \\
\text { (NCT01808573) } \\
\text { Phase III }\end{array}$ & 621 & $32.80 \%$ & 5.6 & 24 & [48] \\
\hline \multirow{3}{*}{$\begin{array}{l}\text { Pertuzumab } \\
\quad(\text { PRT })\end{array}$} & PRT, T & $\begin{array}{c}\text { NCT03001899 } \\
\text { Phase II }\end{array}$ & 66 & $34 \%$ & 5.5 & $\mathrm{n} / \mathrm{a}$ & [49] \\
\hline & $\begin{array}{c}\text { PRT, T, } \\
\text { docetaxel }\end{array}$ & $\begin{array}{c}\text { CLEOPATRA } \\
\text { (NCT00567190) } \\
\text { Phase III }\end{array}$ & 808 & $80.20 \%$ & 18.7 & 56.5 & {$[50,51]$} \\
\hline & $\begin{array}{c}\text { PZB, T, } \\
\text { chemotherapy }\end{array}$ & $\begin{array}{c}\text { APHINITY } \\
\text { (NCT01358877) } \\
\text { Phase III }\end{array}$ & 4805 & $\mathrm{n} / \mathrm{a}$ & $\begin{array}{c}94.1 \% \text { of } \\
\text { patients with } \\
\text { IDFS at } 3 \text { years }\end{array}$ & $\mathrm{n} / \mathrm{a}$ & [52] \\
\hline \multirow[b]{2}{*}{ T-DM1 } & Monotherapy & Phase II & 112 & $25.90 \%$ & 4.6 & $\mathrm{n} / \mathrm{a}$ & [53] \\
\hline & Monotherapy & $\begin{array}{c}\text { EMILA } \\
\text { (NCT00829166) } \\
\text { Phase III }\end{array}$ & 991 & $43.60 \%$ & 9.5 & 30.9 & [54] \\
\hline $\begin{array}{l}\text { T-deruxtecan } \\
\text { (DS-8201; DS) }\end{array}$ & $\begin{array}{c}\text { Monotherapy } \\
\text { (prior } \\
\text { therapies) }\end{array}$ & $\begin{array}{c}\text { DESTINY- } \\
\text { Breast01 } \\
\text { (NCT03248492) } \\
\text { Phase II }\end{array}$ & 184 & $60.90 \%$ & 16.4 & OS not reached & [55] \\
\hline $\begin{array}{l}\text { Tucatinib } \\
\text { (TN) }\end{array}$ & $\mathrm{TN}, \mathrm{T}$, cap & $\begin{array}{c}\text { HER2CLIMB } \\
\text { (NCT02614794) } \\
\text { Phase II }\end{array}$ & 612 & $40.60 \%$ & 7.8 & $\begin{array}{c}44.9 \% \text { at } 2 \\
\text { years }\end{array}$ & [56] \\
\hline \multirow{2}{*}{ Pyrotinib (P) } & $\begin{array}{l}\text { P, cap (prior } \\
\text { therapies) }\end{array}$ & $\begin{array}{c}\text { NCT01937689 } \\
\text { Phase I }\end{array}$ & 38 & $50.00 \%$ & 35.4 & $\mathrm{n} / \mathrm{a}$ & [57] \\
\hline & $\mathrm{P}$, cap & $\begin{array}{c}\text { NCT02422199 } \\
\text { Phase II }\end{array}$ & 128 & $78.50 \%$ & 18.1 & $\mathrm{n} / \mathrm{a}$ & [58] \\
\hline HLX02 & $\begin{array}{l}\text { HLX02, } \\
\text { docetaxel }\end{array}$ & $\begin{array}{l}\text { NCT03084237 } \\
\text { Phase III }\end{array}$ & 649 & $71.30 \%$ & 11.7 & $\mathrm{n} / \mathrm{a}$ & [59] \\
\hline
\end{tabular}




\subsubsection{Lapatinib}

Lapatinib (GW2016) is a synthetic small-molecule reversible inhibitor of EGFR and HER2 tyrosine kinase activity by acting as an ATP-competitive inhibitor. Lapatinib selectively inhibits the kinase activity of EGFR and HER2 and also prevents their autophosphorylation [60]. Konecny et al. [61] evaluated the therapeutic ability of lapatinib using a panel of 31 breast cancer cell lines that also included trastuzumab-resistant HER2-positive breast cancer cells. Lapatinib treatment of HER2-positive breast cancer cell lines was shown to inhibit HER2 and EGFR activity as well as downstream phosphorylation of Akt and ERK. Xenograft mouse models implanted with HER2-positive breast cancer cells showed a significant reduction in tumor volume in the lapatinib treatment group compared to the control group. Furthermore, lapatinib inhibited the growth of trastuzumab-resistant breast cancer cell lines in vitro. Phase II and III clinical trials using lapatinib treatment demonstrated clinical benefit in nearly one third of the patients with advanced HER2-positive breast tumors (Table 1). Although lapatinib was well-tolerated, low-grade adverse effects were frequent [41,43-45]. Despite the clinical benefit of lapatinib, resistance develops through re-activation of mTOR signaling (Figure 1) and up-regulation of nuclear receptor ERR $\alpha$, a key regulator of cell metabolism that is normally degraded in response to lapatinib treatment [62].

\subsubsection{Neratinib}

Neratinib (or HKI-272) inhibits HER2 tyrosine kinase activity by covalent bonding to the cysteine residue of the ATP pocket. In contrast to lapatinib, neratinib is an irreversible inhibitor of HER1, HER2, and HER4, in which it inhibits EGF receptor dimerization and kinase activity [63,64]. Using a panel of 36 breast cancer cell lines, Canonici et al. [64] showed that neratinib was more potent than lapatinib in inhibiting HER2 activity and downstream phosphorylation of Akt and ERK in HER2-positive cell lines, including those that have acquired trastuzumab resistance. Rabindran et al. [63] examined the effects of neratinib using human HER2-positive breast cancer cell lines, where it was found neratinib treatment down-regulated MAPK, Akt, and RB phosphorylation, down-regulated cyclin D1 expression, and up-regulated the cell cycle inhibitor p27 in a dose-dependent manner. Furthermore, preclinical experiments showed that neratinib treatment reduced tumor growth in xenograft mouse models implanted with HER2-positive breast cancer cells compared to the controls $[63,64]$. Furthermore, the combination of neratinib and trastuzumab was more effective at reducing tumor growth than the monotherapies [64]. Phase II trials observed high response rates and median PFS in neratinib treatment of HER2-positive breast cancer (Table 1), but these were lower in patients with prior trastuzumab treatment. Like lapatinib, neratinib was well-tolerated as a monotherapy [47], and resistance to neratinib treatment was also attributed to the hyperactivation of the mTOR signaling pathway (Figure 1) [65]. In the phase III NALA trial, patients previously treated for metastatic HER2-positive breast cancer responded more favorably to neratinib plus capecitabine, particularly HER2positive breast cancer patients that were hormone receptor-negative (HR-) [48]. However, the exteNET trial found that hormone receptor-positive $(\mathrm{HR}+)$ patients responded more favorably to neratinib treatment compared to $\mathrm{HR}$ - patients [66].

\subsubsection{Pertuzumab (2C4)}

Like trastuzumab, pertuzumab (2C4) is a HER2 humanized monoclonal antibody that induces ADCC [67], but pertuzumab binds to a different epitope of the ECD of HER2 than trastuzumab. Pertuzumab inhibits HER2 dimerization with HER3, unlike trastuzumab which inhibits HER2 homodimerization [68]. In preclinical experiments, Scheuer et al. [69] compared the efficacy of pertuzumab, trastuzumab, and both drugs in combination in treating xenograft mouse models of cancer. They found that monotherapy of pertuzumab reduced the tumor volume to a similar extent as the trastuzumab treatment, but tumor growth was significantly quenched with dual therapy of both monoclonal antibodies. Phase II studies found pertuzumab/trastuzumab combined therapy was successful in treating 
HER2-positive breast cancer (Table 1), with more than $10 \%$ of patients experiencing adverse effects, but the therapy was otherwise well-tolerated [49-51]. In the phase III Cleopatra (CLinical Evaluation Of Pertuzumab And TRAstuzumab) study, Baselga et al. [50] treated 808 patients with pertuzumab plus trastuzumab plus docetaxel (an inhibitor of tubulin assembly/disassembly) or trastuzumab plus docetaxel as the control group. Here, the addition of pertuzumab significantly increased PFS by several months without any increase in cardiac toxicity (Table 1). In the APHINITY clinical trials [52,70], patients with early HER2-positive breast cancer were treated with pertuzumab or placebo in combination with trastuzumab and chemotherapy. HER2-positive breast cancer patients treated with pertuzumab showed significant improvement in the 3-year invasive disease-free survival rate compared to the placebo group. Furthermore, disease recurrence in the pertuzumab group was reduced. Much like the phase II studies, the addition of pertuzumab to a trastuzumab and chemotherapy treatment regimen did not result in any significant increase in adverse effects other than elevated diarrhea scores [70].

\subsubsection{Trastuzumab Antibody-Drug Conjugates}

Trastuzumab emtansine (trastuzumab-DM1) is an antibody-drug conjugate where trastuzumab is stably bound to DM1, a derivative of anti-tumor drug maytansine. Trastuzumab-DM1 binds to HER2 and is subsequently internalized, where DM1 is released and inhibits microtubule assembly/disassembly and cell proliferation. In phase II clinical trials, trastuzumab-DM1 monotherapy showed similar success compared to other HER2 therapies in HER2-positive breast cancer (Table 1) and was well-tolerated with only $\sim 20 \%$ of patients experiencing adverse effects [53]. Another trastuzumab antibody-drug conjugate is trastuzumab deruxtecan (DS-8201), which is trastuzumab linked to a cytotoxic topoisomerase I inhibitor by a tetrapeptide-based linker that is selectively cleaved by cathepsins, which are up-regulated in the tumor cells. In contrast to trastuzumab-DM1, DS-8201 releases a drug with improved cell membrane permeability and has a shorter half-life [71,72]. In phase II clinical trials, DS-8201 showed an ORR of $60.2 \%$ in patients with HER2-positive metastatic breast cancer [55]. Anti-tumor effects were even observed in patients with low HER2 expression. Although gastrointestinal and hematologic toxicity was a common occurrence in patients during treatment, no cardiotoxicity was observed, but an increased risk of interstitial lung disease was associated with treatment.

\subsubsection{Tucatinib}

Like lapatinib, tucatinib binds to the ATP pocket of HER2 and acts as a competitive, reversible tyrosine kinase inhibitor, but tucatinib is selective for HER2 only [73]. Kulukian et al. [73] also determined that tucatinib effectively inhibited HER2 phosphorylation in vitro using the HER2-positive breast cancer cell line BT-474 and observed a minimal inhibition of EGFR phosphorylation in the EGFR-overexpressing skin cancer cell line A431. In xenograft mouse models of HER2-positive breast cancer implanted with BT-474 cells, tucatinib treatment resulted in a delay in tumor growth comparable to trastuzumab monotherapy, and these effects were enhanced in the combination therapy of tucatinib plus trastuzumab [73]. In HER2CLIMB, a phase II clinical trial, tucatinib-trastuzumab-capecitabine combination therapy for HER2-positive breast cancer showed a higher ORR and median PFS than the placebo-trastuzumab-capecitabine group (Table 1); however, this was associated with a high incidence of adverse effects [56].

\subsubsection{Pyrotinib}

Pyrotinib (or SHR1258) is an irreversible inhibitor of EGFR/HER1, HER2, and HER4 shown to suppress tumor growth in HER2-positive breast cancer xenograft mouse models, which was associated with a favorable safety profile [74]. In phase I and II clinical trials, Ma et al. $[57,58]$ reported that the combination therapy of pyrotinib and capecitabine resulted in significantly improved ORR and PFS as compared to lapatinib and capecitabine therapy 
(Table 1). Pyrotinib treatment was also well-tolerated, with a low percentage of patients experiencing grade 3 adverse events.

\subsubsection{HLX02}

Although success using trastuzumab to treat HER2-positive breast cancer has been achieved, the expensiveness of this drug limits accessibility to patients. Hence, biosimilar drugs ameliorate this issue as they are nearly indistinguishable from the original drug and are less expensive. Recently, a biosimilar to trastuzumab, HLX02 [75], was shown to have near-identical clinical results when compared to trastuzumab [76]. Xu et al. [59] reported that HXL02 showed similar efficacy and adverse effects in patients with HER2-positive recurrent or metastatic breast cancer compared to patients receiving trastuzumab (Table 1).

\section{The mTOR Pathway in HER2-Positive Breast Cancer}

\section{1. mTOR Protein Structure and Function}

Enhanced activity of mTOR is associated with HER2-overexpressing breast cancers $[77,78]$. The mTOR protein contains five domains: (i) the Huntington, EF3A, ATM, TOR (HEAT) repeats, (ii) the helical Frap, ATM, TRRAP (FAT) domain, (iii) FKBP-rapamycin complex binding (FRB), (iv) the kinase domain, and (v) FAT C-terminal (FATC). mTOR is the catalytic subunit in two protein complexes, mTOR complex 1 (mTORC1) and mTOR complex 2 (mTORC2). mTORC1 is composed of five components: mTOR, regulatoryassociated protein of mTOR (raptor), mammalian lethal with Sec13 protein 8 (mLST8 or $\mathrm{G} \beta \mathrm{L})$, proline-rich Akt substrate $40 \mathrm{kDa}$ (PRAS40), and DEP-domain-containing mTORinteracting protein (deptor). Like mTORC1, mTORC2 also contains mTOR, mLST8, and deptor, but has the rapamycin-insensitive companion of mTOR (rictor), mammalian stressactivated protein kinase interacting protein (mSIN1), and protein observed with Rictor-1 (Protor-1) subunits [79]. Raptor mediates mTORC1 binding to the substrates for phosphorylation [80]. Rictor is unrelated to raptor but facilitates the phosphorylation of various substrates of mTORC2 [81].

\subsection{Regulation of mTOR Pathway}

Serine-threonine kinase LKB1 (STK11, also referred to as Liver Kinase 1), is a tumor suppressor that negatively regulates mTORC1 activity. LKB1 functions within a heterotrimer, containing the pseudokinase STRAD and the adaptor protein MO25 [82-84], that activates AMPK by phosphorylation on T172 (Figure 1; [85]). AMPK, also a serinethreonine kinase, is a metabolic sensor and negative regulator of the mTOR signaling pathways. The AMPK protein is composed of the catalytic $\alpha$ subunit and the regulatory $\beta$ and $\gamma$ subunits. AMPK activation is induced by energy-stressed conditions in which intracellular AMP levels are elevated. AMP activates AMPK by binding to the $\gamma$ subunit and subsequently targeting it for phosphorylation by LKB1 on T172 [86]. AMPK activates the tuberous sclerosis complex 1 and 2 (TSC1/2) by phosphorylation of T1227 and S1345 on TSC2 [87]. Activated TSC1/2 acts as a GTPase activating protein (GAP) that inhibits the small GTPase Ras Homolog Enriched in Brain (Rheb), which is involved in mTORC1 activation [88]. In addition, AMPK can directly inhibit mTORC1 by phosphorylation of raptor on $\mathrm{S} 722$ and $\mathrm{S} 792$ [89].

The PI3K-Akt pathway is an important regulator of the mTOR pathway. The Akt protein consists of three main domains: the N-terminal pleckstrin homology $(\mathrm{PH})$ domain, the central kinase catalytic (CAT) domain, and the C-terminal extension (EXT) region. The $\mathrm{PH}$ domain mediates the protein-protein and protein-lipid interactions of Akt. The CAT domain mediates enzymatic activity and contains T308, a phosphoinositide-dependent kinase 1 (PDK1)-dependent phosphorylation site necessary for Akt activation [90]. The EXT region contains S473 phosphorylation for full Akt activation (reviewed in [91]). Akt enables mTOR activity by inactivating TSC $1 / 2$ through the phosphorylation of TSC2 on several residues, hence enabling Rheb-GTPase to activate mTORC1 (Figure 1; [92]). Akt can also directly activate mTORC1 by phosphorylation of mTOR on S2448 [93]. 
The cyclic adenosine $3^{\prime}, 5^{\prime}$-monophosphate (cAMP)-dependent protein kinase A (PKA) is a key regulator of the mTOR pathway, and both are up-regulated in metastatic breast cancer [78]. PKA consists of two catalytic subunits and two regulatory subunits and can be activated under glucose-deprived conditions where an accumulation of cellular levels of cAMP occurs. Activation of PKA by cAMP occurs when cAMP binds to the regulatory subunits of $\mathrm{PKA}$, which dissociates them from the catalytic subunits that are responsible for PKA activities [94-96]. Once activated, PKA promotes the phosphorylation and activation of AMPK in an LKB1-dependent manner [97], which then leads to the inhibition of mTORC1 by phosphorylation of raptor on S791 [98]. The study by Kari et al. [97] found that the knockout of LKB1 significantly reduced AMPK phosphorylation in response to PKA activation; however, the reduction in LKB1 did not completely ablate this effect, possibly due to residual LKB1. They also speculated that AMPK phosphorylation is mediated by another kinase. Other than LKB1, $\mathrm{Ca}^{2+} /$ calmodulin-dependent protein kinase kinase 2 (CaMKK2) [99] and transforming growth factor- $\beta$ (TGF- $\beta$ )-activated kinase 1 (TAK1) $[100,101]$ are both known to phosphorylate AMPK on T172. Since this review is focused on discussing the role of AMPK in regulating the mTOR pathway, further discussion regarding the regulation of AMPK has been reviewed in detail elsewhere [102].

\subsection{Downstream of mTOR Pathway}

\subsection{1. mTORC1 Activation of S6K1 and 4E-BP1}

mTORC1 activates translational regulators p70 ribosomal S6 kinase 1 (S6K1) and eukaryotic initiation factor 4E (eIF4E)-binding protein 1 (4E-BP1) (Figure 1). 4E-BP1 acts as a translational inhibitor by binding to eIF4, thus inhibiting eIF4 from binding with eIF4G. This prevents incorporation of eIF4E into the eIF4F complex, consequently halting 5'-capdependent translation [103]. mTORC1 phosphorylates 4E-BP1 on T37 and T46, which primes 4E-BP1 for subsequent phosphorylation that dissociates it from eIF4E, thereby enabling 5'-cap-dependent translation [104]. Activated mTORC1 also mediates S6K1 activity by binding to the eIF3 complex with S6K1. mTORC1 then phosphorylates S6K1, leading to its dissociating from the eIF3 complex, which subsequently allows S6K1 activity [105].

\subsection{2. mTORC1 Regulation of Cell Cycle}

Activation of mTORC1 also stimulates cell cycle progression through S6K1 and 4E-BP1. Fingar et al. [106] showed that inhibition of mTORC1 activity and knockdown of S6K1 and 4E-BP1 all resulted in the inhibition of G1 phase progression in U2OS osteosarcoma cells. Averous et al. [107] showed that mTORC1 regulated the expression of cyclin D1, an essential regulator of the G1/S phase transition, in a 4E-BP1-dependent manner. Inhibition of mTORC1 activity down-regulated cyclin D1 mRNA and protein levels in MCF7 breast cancer cells, but this effect was rescued when eIF4E activity was enhanced by the knockdown of 4E-BP1. Enhanced activity of eIF4E also increased cyclin D1 translation as knockdown of 4E-BP1 resulted in an increased association of polysomes to the cyclin D1 mRNA. Furthermore, overexpression of 4E-BP1, in the absence of active mTORC1, led to decreased cyclin D1 levels. Knudson et al. [108] observed cyclins A, D1, and E1 were all down-regulated in response to dual inhibition of mTORC1 and mTORC2, knockdown of raptor, and dual knockdown of raptor and rictor.

\subsection{3. mTORC1 Regulation of Akt}

Although Akt is a positive regulator of mTORC1 activation, mTORC1 negatively regulates Akt activation by modulating its activation by insulin receptor substrate-1 (IRS-1). mTORC1-activated S6K1 inactivates IRS-1 by phosphorylation on S422 [109], leading to its proteasomal degradation [110]. The mTORC1-dependent activation of S6K1 negatively regulates the ERK/MAPK pathway. Inhibition of mTORC1 up-regulated phosphorylated ERK (T202/Y204) levels, which was ablated by the overexpression of constitutively active S6K1 [111]. 


\subsection{4. mTORC1 Regulation of Glycolysis}

The mTOR pathway has been implicated as a key regulator of metabolic functions. mTORC1 is involved in glucose uptake and glycolysis by up-regulating the activation of transcription factors such as HIF1 $\alpha$. Using murine embryonic fibroblasts (MEFs) from wild-type, $T s 1^{-/-}$, and $T s c 2^{-/-}$mice, Duvel et al. [112] demonstrated that activated mTORC1 caused an elevated expression of HIF1 $\alpha$ in Tsc2 ${ }^{-/-}$MEFs, but not in Rictor ${ }^{-/-}$ MEFs. The mTORC1-dependent up-regulation of HIF1 $\alpha$ was shown to be dependent on 4E-BP1 and not S6K1. Knockdown of raptor or inhibition of mTORC1 activity both downregulated transcript levels of glycolytic enzymes Glut1, Pfkp, and Pdk1, which was consistent with the knockdown of HIF1 $\alpha$. Increased glucose uptake due to mTOR hyperactivation was observed in $T s c 2^{-/-}$MEFs, and this effect was blocked by knockdown of HIF1 and inhibition of mTORC1 activity, thus indicating that mTORC1 mediated the increase in glucose uptake through HIF1 $\alpha$. Finlay et al. [113] also demonstrated that activation of mTORC1, independent of the PI3K-Akt pathway, was found to up-regulate the expression of HIF1 $\alpha$ in CD8 ${ }^{+}$T cells. Poulain et al. [114] examined the effect of mTORC1 activation on glycolytic activity in acute myeloid leukemia (AML) cells. Hyperactive mTORC1 in AML cells was observed to enhance glycolysis and establish a dependency on glycolysis for survival. Furthermore, transcriptome analysis of AML cell line MOLM-14 treated with an inhibitor of MTORC1 showed a down-regulation of genes involved in glycolysis and PPP. Furthermore, inhibition of $\mathrm{mTORC} 1$ also reduced glucose uptake and lactate production in four different AML cells with hyperactive mTOR signaling. In addition to its role in glucose metabolism, mTORC1 also regulates lipid/cholesterol metabolism. mTORC1 was shown to mediate the activity of two transcription factors that regulate lipid and cholesterol homeostasis, sterol regulatory element-binding protein (SREBP) [112,115], and peroxisome proliferator-activated receptor- $\gamma(\operatorname{PPAR} \gamma)$ [116].

\subsection{5. mTORC1 Regulation of Mitochondrial Biogenesis}

mTORC1 was found to be essential for mitochondrial biogenesis and activity in a 4EBP1-dependent manner in vitro and in vivo. Inhibition of mTORC1 or raptor knockdown both down-regulated transcription of genes involved in oxidative phosphorylation and genes encoding mitochondrial ribosomal proteins and reduced mitochondrial respiration, intracellular ATP levels, and mitochondrial DNA content [117]. Cunningham et al. [118] observed that the inhibition of mTORC1 resulted in the down-regulation of several genes involved in mitochondrial function and reduced mitochondrial respiration. mTORC1 also interacts with the transcriptional regulators yin-yang 1 (YY1) and peroxisome-proliferator activated receptor coactivator-1a (PGC-1a), involved in mitochondrial biogenesis and oxidative metabolism. Consistent with these findings, the loss of mTORC1 activity in the skeletal muscle from conditional knockout of raptor in mice also showed a reduction in transcript levels of PGC-1a and its target gene myoglobin, protein levels of the PGC-1a co-activator PPAR $\gamma$ and the mitochondrial marker cytochrome $c$ oxidase IV (COX IV), and oxygen capacity [119]. Morita et al. [117] demonstrated the involvement of mTORC1 in regulating mitochondrial biogenesis and activity in a 4E-BP1-dependent manner in vitro and in vivo. They found that inhibition of mTORC1 modulated the mRNA levels of several genes comprising the components of complex $\mathrm{V}$ of the oxidative phosphorylation pathway, TFAM (a regulator of mitochondrial DNA replication and transcription), numerous mitochondrial ribosomal proteins (MRPLs), and NADH dehydrogenase 1 alpha subcomplex assembly factors 2 and 4 (NDUFAF2 and 4). The knockdown of mTORC1 subunit raptor resulted in a reduction in ATP synthase subunit ATP5O and TFAM expression, mitochondrial respiration, TCA intermediates pyruvate and lactate, and intracellular ATP levels and mitochondrial DNA content as compared to the control.

\subsection{6. mTORC1 Regulation of Autophagy}

mTORC1 is a positive regulator of cell growth by repressing autophagy through inhibition of unc-51-like kinase 1 (ULK1) [120], a kinase that initiates autophagy by pro- 
moting autophagosome formation. ULK1 is present as a complex with autophagy-related gene-13 (ATG13), autophagy-related gene-101 (ATG101), and focal adhesion kinase familyinteracting protein of $200 \mathrm{kDa}$ (FIP200). In glucose-starved conditions, ULK1 interacts with AMPK and is subsequently activated by phosphorylation on S317 and S777. In nutrient-sufficient conditions, mTORC1 phosphorylates ULK1 on S757, which prevents autophagosome formation by disrupting the interaction of ULK1 with AMPK [121].

\subsection{7. mTORC1 Regulation of mTORC2}

The activation of mTORC1 maintains a feedback loop that inhibits mTORC2 activity. This negative feedback loop is initiated by mTORC1 phosphorylation of S6K1 that subsequently phosphorylates the mTORC2 subunits rictor on T1153 and mSin1 on Thr86 and Thr398 [122-124]. The phosphorylation of rictor did not affect mTORC2 assembly, kinase activity, or cellular localization; however, mutation of T1153 resulted in increased mTORC2 activity [122]. In contrast, the phosphorylation of mSin1 causes the dissociation of $\mathrm{mSin} 1$ from mTORC2, thus preventing mTORC2 activity [124]. AMPK activation can affect the negative feedback loop by inhibiting $\mathrm{MTORC} 1$ and alleviating the inhibition of mTORC2 [125]. Gao et al. [125] showed that the non-steroidal anti-inflammatory drug aspirin induced the activation of AMPK, leading to the up-regulation of mTORC2-dependent phosphorylation of Akt (S473), which was prevented by knockdown of rictor in hepatoma cell line HepG2 and colon cancer cell line SW480.

\subsubsection{Downstream of mTORC2}

The AGC family of kinases, including Akt, PKC $\alpha$, and SGK1, is composed of substrates of mTORC2 and facilitates mTORC 2 modulation of the actin cytoskeletal structure, cell survival, and proliferation [81]. Activation of mTORC2 was found to stimulate phosphorylation of protein kinase $\mathrm{C} \alpha(\mathrm{PKC} \alpha)$ on S657. Knockdown of rictor and mTOR in HeLa cells both resulted in thick cytoplasmic actin fibers and less cortical actin staining than the control, like the knockdown of PKC $\alpha[81,126]$. In addition, cell survival and proliferation are mediated by mTORC2 via priming Akt for activation through phosphorylation on S473, leading to full activation of Akt by phosphorylation on T308 by PDK1 [127]. Studies have demonstrated that depletion of rictor, $\mathrm{mLST} 8$, or mSIN1 of mTORC2 resulted in the ablation of the Akt phosphorylation on S473 [128-130].

\subsection{9. mTORC2 Regulation of Glycolysis}

Much like mTORC1, mTORC2 is involved in the regulation of glycolysis but through distinct mechanisms. Hagiwara et al. [131] investigated the involvement of mTORC2 in glycolysis using mice with liver-specific knockout of rictor (LiRiKO mice). Livers from the LiRiKO mice showed a significant reduction in Akt phosphorylation on S473 and T450, both mTORC2 phosphorylation sites, but loss of rictor did not affect the phosphorylation of T308, the PDK phosphorylation site. Furthermore, glycolysis appeared to be negatively affected by the loss of rictor as several genes involved in glycolysis (glucokinase, pyruvate kinase, ChREBP) were down-regulated, as well as the protein expression and enzymatic activity of glucokinase. By introducing a constitutively active form of Akt, the effects caused by the loss of rictor were reversed, indicating that mTORC2 mediated glycolysis in an Akt-dependent manner. Masui et al. [132] examined the role of mTORC2 in glycolysis in glioblastoma (GBM) through c-Myc, a critical regulator of cancer cell metabolism. Rictor shRNA knockdown in GBM cells reduced the expression of c-Myc as well as genes involved in glycolysis (Ldha, Hk2, Pdk1, Eno1, Glut1) and the pentose phosphate pathway (PPP) (G6pd, Pgd, Rpe, Rpia). The down-regulation of these genes was concomitant with dramatically reduced glucose consumption, lactate production, glutamine uptake, and glutamate secretion. In addition, mTORC2 was shown to regulate c-Myc expression by promoting the phosphorylation and inactivation of histone deacetylases, consequently allowing acetylation of the transcription factors FOXO1 and FOXO3 that alleviated the miR-34c-dependent repression of c-Myc. Unlike rictor knockdown, shRNA knockdown 
of raptor or Akt had only a modest effect on c-Myc expression. This also indicated that mTORC2 could regulate glycolysis independently of Akt. More recently, $\mathrm{Zu}$ et al. [133] examined the involvement of mTORC2 in a c-Myc-driven mouse model of hepatocellular carcinoma (HCC), in which ablation of rictor prevented the development of HCC in vivo. These mice also show an up-regulation of phosphorylated Akt on S473 compared to livers of wild-type mice, suggesting the c-Myc may also regulate mTORC2. Much like rictor ablation, ablation of Akt1, but not Akt2, also prevented HCC in vivo. This study indicated that mTORC2 and Akt1 are required for c-Myc-driven HCC. Together, these studies highlight that $\mathrm{mTORC} 2$ regulates glycolysis through activation of Akt and c-Myc, depending on the context. This contrasts with mTORC1 that regulates glycolysis via other factors including HIF1 $\alpha$ and SREBP1.

\subsubsection{Role of $\mathrm{mTORC} 1$ and $\mathrm{mTORC} 2$ in Immunity}

Both mTORC1 and mTORC2 are involved in innate and adaptive immunity. The mTOR pathways are essential for many immune functions that include suppression of IL12 and IL-23 production, enhancing M2 macrophage polarization, antigen presentation, and innate immune cell migration. Activation of mTOR in immune cells and other cell types within the tumor microenvironment also affects cancer progression through supporting angiogenesis, metastasis, and drug resistance. The immunological roles of mTOR signaling and its involvement in the tumor microenvironment will not be discussed in this review but have been reviewed in detail elsewhere [134,135].

\section{4. mTOR Pathway Inhibitors: Mechanisms of Action and Efficacy in Clinical Studies for the Treatment of HER2-Positive Breast Cancer}

\subsubsection{Rapamycin (Sirolimus) and Rapalogs}

Rapamycin (sirolimus) is the first mTOR inhibitor discovered as a naturally occurring compound purified from the bacterium Steptomyces hygroscopicus. Rapamycin and its analogs, or rapalogs, inhibit mTORC1 kinase activity by binding to the small mTORbinding protein FK506-binding protein 12 (FKBP12), and then irreversibly binding to the FRB domain of mTOR, thereby inhibiting the kinase activity of the adjacent catalytic domain [136,137]. In contrast to mTORC1, the mTOR subunit of mTORC2 is insensitive to rapamycin; however, prolonged treatment can disrupt mTORC2 assembly in certain cell types whereby the mTOR protein is unavailable for assembly into mTORC2 as it is sequestered in a complex with rapamycin [138] (reviewed in [139]).

The synthetically made rapalogs were designed to improve the pharmacokinetic properties relative to rapamycin. Like rapamycin, rapalogs are metabolized by the liver, and in the intestine via cytochrome P450 enzyme CYP-3A4 [140]. The rapalogs' metabolites are eliminated mainly through the gastrointestinal tract (reviewed in [141]). Temsirolimus (CCI779) is one of the first rapalogs and a rapamycin prodrug developed with a higher water solubility than rapamycin to allow intravenous injection and oral administration [142]. Everolimus (EVE; RAD001) is a non-prodrug designed to have improved oral bioavailability and a shorter half-life compared to rapamycin [143]. Everolimus also inhibits mTORC1 kinase activity and activation of its downstream effectors S6K1 and 4E-BP1 as well as the expression of the proangiogenic transcription factor hypoxia-inducible factor 1a (HIF1a) $[144,145]$. Ridaforolimus (AP23573, deforolimus) is a non-prodrug rapalog that is designed to combine the improvements of temsirolimus and everolimus whereby water solubility, chemical stability, and bioavailability are improved compared to rapamycin and can be administered orally or intravenously [146]. One of the more serious issues with rapamycin and rapalogs is the induction of Akt and ERK signaling in cancer cells (Figure 1) that is caused by activation of mTORC2 due to mTORC1 inhibition, as discussed previously [111,147] (for further details, see review [148]). Rapamycin treatment of breast cancer cell lines MCF-7 and MDA-MB-468 and the prostate cancer cell line DU-145 (PTEN wild type) all resulted in a significant up-regulation of Akt phosphorylation on S473 [147]. Akt activation in cancer cells is an unfavorable effect of mTORC1 inhibition as Akt promotes 
survival and proliferation [147]. Hence, mTORC1 inhibition stimulating Akt and ERK signaling is an unfavorable effect in cancer therapy as this promotes tumor survival and proliferation [111].

\subsection{2. mTOR Kinase Inhibitors (TKIs)}

Second-generation mTOR kinase inhibitors (TKIs) act as competitive ATP inhibitors by binding to the kinase domain of the mTOR subunit present in both mTORC1 and mTORC2, consequently blocking their catalytic activity. Furthermore, TKIs have the advantage over rapamycin and rapalogs as TKIs block the feedback activation of PI3K-Akt signaling resulting from mTORC1 inhibition [139]. Torin-1 is a TKI highly selective for mTOR and does not affect the stability of mTOR complexes [149]. AZD8055 inhibits the mTOR subunit of both mTORC1 and mTORC2, and class I PI3K isoforms [150,151]. Furthermore, AZD8055 treatment impaired cell proliferation of several cancer cell lines and impaired tumor growth in xenograft mouse models [150]. AZD2014 (vistusertib), an analog of AZD8055 with improved properties, is also a potent ATP-competitive inhibitor selective for mTORC1 and mTORC2 [152]. AZD2014 was shown to inhibit the phosphorylation of mTORC1 and mTORC2 substrates in vitro and in vivo. Although everolimus was found to be a more potent inhibitor of mTORC1 activity than AZD2014, cell proliferation was inhibited more effectively by AZD2014. In xenograft mice implanted with MCF-7 cells, an ER-positive and PR-positive breast cancer cell line, treatment using AZD2014 or the selective estrogen receptor degrader fulvestrant and the combination of the two drugs were assessed. The combination of both AZD2014 and fulvestrant was found to be more effective in inhibiting tumor growth than either drug alone, and patients receiving this combination treatment presented with low toxicities [152]. Although TKIs are an improvement compared to rapamycin and its analogs, they have shown a minimal effect in reducing lung tumor growth in mice with mutant K-Ras [153], and there is greater toxicity associated with these drugs [154]. In the MANTA phase II clinical trial, treatment of ER+ breast cancer patients using fulvestrant plus vistusertib therapy was less effective as PFS was lower compared to fulvestrant plus everolimus therapy [155]. Prolonged inhibition of mTORC2 was found to increase Akt phosphorylation on T308 without the presence of Akt phosphorylation on S473, suggesting a possible mechanism of resistance [139]. A phase I clinical trial assessed the therapeutic use of another dual mTORC1/2 inhibitor, CC-223, for patients with advanced solid tumors or multiple myeloma [156]. CC-223 was well-tolerated with a low number of grade 3 toxicities and other manageable toxicities. In phase II clinical trials using patients with non-pancreatic neuroendocrine tumors, CC-223 therapy achieved a median PFS of 19.5 months, an ORR of $7.3 \%$, and a disease control rate of $90.2 \%$, and a tumor size reduction of any magnitude was observed in $73.2 \%$ of patients [157]. This demonstrated that dual mTORC1/2 inhibition may be an effective treatment for this and other types of cancer.

\subsubsection{Dual PI3K-mTOR Inhibitors}

The dual PI3K-mTOR inhibitors are small-molecule inhibitors related to TKIs that bind to the ATP-binding sites of PI3K and mTOR with similar affinity. NVP-BEZ235 inhibits both mTOR and PI3K signaling in vitro and in vivo [151,158]. Furthermore, NVP-BEZ235 has been shown to suppress the growth of hypopharyngeal squamous cell carcinoma (HSCC) cell line FaDu in vitro and in xenograft mouse models. However, clinical trials observed that NVP-BEZ235 therapy was associated with high toxicity and little to no clinical improvement, leading to discontinuation of the treatment [159-161]. PI-103 is an inhibitor of mTORC1, mTORC2, DNA-PK, and several PI3K isoforms. Thus far, PI-103 was demonstrated to inhibit the proliferation of various cancer cell lines and tumor growth in xenograft mouse models $[162,163]$. 


\subsection{Clinical Response of mTOR Inhibition in HER2-Positive Breast Cancer Patients}

Clinical trials have assessed the efficacy of rapalogs in combination with trastuzumab for the treatment of HER2-positive breast cancer. In a phase I study, everolimus, trastuzumab, and paclitaxel combination therapy of HER2-positive breast cancer showed promising results with an ORR of $44 \%$ and median PFS of 34 weeks (Table 2); however, grade 3 to 4 neutropenia was common in patients [164]. In the BOLERO-1 phase III clinical trial $[165,166]$, everolimus, trastuzumab, and paclitaxel combination therapy for HER2-positive breast cancer showed an objective response, and median PFS was similar between patients who received the addition of everolimus to the trastuzumab and paclitaxel therapy compared to the addition of the placebo. Interestingly, patients with HER2-positive/hormone receptornegative (HR-) status showed an improved median PFS compared to the placebo group (20.27 months vs. 13.08 months) (Table 2). In the BOLERO-3 phase III clinical trial [167], everolimus, trastuzumab, and mitotic inhibitor vinorelbine combination therapy of patients with trastuzumab-resistant, HER2-positive breast cancer showed minor improvements in response and median PFS (Table 2). In both BOLERO-1 and BOLERO-3 trials, toxicity was more frequent for patients receiving everolimus than in the placebo groups. Another rapalog, ridaforolimus, used in combination with trastuzumab therapy showed some success in clinical benefit rates and median PFS (Table 2) with modest toxicities [168]. In the LCCC 1025 phase II clinical trial [169], everolimus, trastuzumab, and vinorelbine combined therapy for HER2-positive breast cancer patients with brain metastases showed similar clinical benefit rates relative to other clinical studies using everolimus for HER2-positive breast cancer therapy (Table 2). Together, these clinical trials observed that combining rapalogs and trastuzumab presented a slight improvement in clinical benefits compared to HER2 inhibition alone. However, mTORC1 inhibition resulted in a higher incidence of low-grade and grades 3-4 toxicities. Furthermore, these studies assessed the efficacy of rapalogs that inhibit mTORC1 and not mTORC2 [170,171]. Inhibition of mTORC1 promotes mTORC2 activation and hence mTORC2-dependent feedback activation of the Akt signaling pathway $[127,171]$, thus promoting cancer cell survival and proliferation. Interestingly, in preclinical studies and in vitro, $\mathrm{O}^{\prime} \mathrm{Brien}$ et al. demonstrated that combined inhibition of Akt and mTOR prevented the feedback activation induced by trastuzumab-mediated inhibition of mTORC1 and sensitized trastuzumab-resistant cells to trastuzumab [172].

For the dual PI3K-mTOR inhibitors, clinical trials assessing the efficacy of NVPBEZ235 therapy for prostate cancer [159], renal cell carcinoma [160], and solid tumors [161] observed high toxicity and no improvement in clinical responses. More recently, the maximum tolerated dose of NVP-BEZ235, as well as formulations and dosage forms, were assessed in patients with solid tumors, including those with HER2-positive breast cancer [173]. Here, Rodon et al. reported that the adverse effects of NVP-BEZ235 monotherapy, in any formulation, and when used in combination with trastuzumab, were similar. The authors noted that the onset of the adverse effects occurred shortly after dosing and may be caused by low absorption and precipitation of the drug at high doses rather than mechanism-based toxicities. Furthermore, certain toxicities associated with PI3K inhibition (hyperglycemia and rash) and mTOR inhibition (pneumonitis) were not observed [173]. Despite this, an anti-tumor effect with a favorable safety profile could not be achieved with any NVP-BEZ235 treatments or formulations.

This review focuses on the clinical efficacy and toxicity of mTOR inhibitors in HER2positive breast cancer, but these have been assessed in many other cancers. For further details of the clinical efficacy of mTOR inhibitors in cancers other than HER2-positive breast cancer, please refer to reviews: [174,175]. 
Table 2. Clinical trials targeting mTOR in HER2-positive breast cancer.

\begin{tabular}{|c|c|c|c|c|c|c|c|}
\hline Treatme & & Trial Name & Patients & ORR & Median PFS & $\begin{array}{c}\text { OS } \\
\text { (Months) }\end{array}$ & REF \\
\hline \multirow{6}{*}{ Everolimus } & $\mathrm{EV}, \mathrm{V}, \mathrm{T}$ & $\begin{array}{c}\text { NCT0046556 } \\
\text { Phase Ib/II }\end{array}$ & 33 & $44.00 \%$ & 34 weeks & $\mathrm{n} / \mathrm{a}$ & [164] \\
\hline & EV, EX & $\begin{array}{c}\text { NCT00426530 } \\
\text { Phase Ib }\end{array}$ & 50 & $19.10 \%$ & 30.7 weeks & $\mathrm{n} / \mathrm{a}$ & [176] \\
\hline & & \multirow{2}{*}{$\begin{array}{c}\text { BOLERO-1 } \\
\text { (NCT00876395) } \\
\text { Phase III }\end{array}$} & 719 & $67.00 \%$ & 14.95 months & $\begin{array}{c}63 \% \text { survival at } \\
41.3\end{array}$ & [165] \\
\hline & $\mathrm{EV}, \mathrm{P}, \mathrm{T}$ & & $\begin{array}{c}303 \\
\text { (Asian subset) }\end{array}$ & $69.20 \%$ & $\begin{array}{l}18.40 \text { months, } \\
25.46 \text { months } \\
\text { (HR-) }\end{array}$ & $\mathrm{n} / \mathrm{a}$ & [166] \\
\hline & $\mathrm{EV}, \mathrm{P}, \mathrm{T}$ & $\begin{array}{c}\text { BOLERO-3 } \\
\text { (NCT01007942) } \\
\text { Phase III }\end{array}$ & 569 & $41.00 \%$ & 7 months & $\mathrm{n} / \mathrm{a}$ & [167] \\
\hline & $\mathrm{EV}, \mathrm{P}, \mathrm{T}$ & $\begin{array}{c}\text { LCCC } 1025 \\
\text { (NCT01305941) } \\
\text { Phase II }\end{array}$ & 32 & $\begin{array}{c}\text { CBR: } 20 \%(>6 \\
\text { months), IRR: } 4 \%\end{array}$ & $\begin{array}{l}3.93 \text { months } \\
\text { (TTP) }\end{array}$ & 12.2 & [169] \\
\hline Ridaforolimus & $\mathrm{R}, \mathrm{T}$ & $\begin{array}{l}\text { NCT00736970 } \\
\text { Phase IIb }\end{array}$ & 34 & CBR: $34.3 \%$ & 5.4 months & 17.7 & [168] \\
\hline \multirow{2}{*}{$\begin{array}{l}\text { Dactolisib } \\
\text { (BEZ235) }\end{array}$} & B & \multirow{2}{*}{$\begin{array}{l}\text { NCT00620594 } \\
\text { PhaseI/Ib }\end{array}$} & 153 & $0 \%$ & SD: $31.1-42.4 \%$ & $\mathrm{n} / \mathrm{a}$ & \multirow{2}{*}{ [173] } \\
\hline & $\mathrm{B}, \mathrm{T}$ & & 30 & $13.30 \%$ & SD: $40 \%$ & $\mathrm{n} / \mathrm{a}$ & \\
\hline
\end{tabular}

$\mathrm{CBR}=$ clinical benefit rate, $\mathrm{TTP}=$ time to intercranial progression, $\mathrm{IRR}=$ intracranial response rate, $\mathrm{SD}=\mathrm{stable}$ disease, $\mathrm{EV}=\mathrm{everolimus,}$ $\mathrm{EX}=$ exemestane, $\mathrm{P}=$ pacitataxel, $\mathrm{T}=$ trastuzumab, $\mathrm{V}=$ vinorelbine, $\mathrm{B}=\mathrm{BEZ235}, \mathrm{HR}=$ hormone receptor.

\subsection{Preclinical Studies of mTOR Pathway in HER2-Positive Breast Cancer Mouse Models}

Genetically engineered mouse models of HER2-positive breast cancer overexpress Neu/HER2 (wild-type or mutant Neu) in mammary glands under the Mouse Mammary Tumor Virus (MMTV) promoter. The first Neu/HER mouse model, MMTV-neu mice, was initially described in 1988 by the Leder laboratory [177]. MMTV-neu mice constitutively express Neu/HER2 and produce rapidly growing, highly metastatic mammary tumors [177] (reviewed in [178]). Later, in 2008, MMTV-NIC (neu-IRES-Cre) mice were generated, which simultaneously expresses neu and cre recombinase (activated Neu/HER2-MMTV-Cre) under the endogenous Erbb2 promoter. NIC mice produce aggressive HER2-positive mammary tumors at around 146 days old [179].

When human breast cancer tissue microarrays were analyzed for expression of LKB1, a critical negative regulator of $\mathrm{mTORC} 1,31 \%$ of HER2-positive breast cancers were deficient in LKB1 expression [77]. Based on those observations, Lkb1 (also known as Stk11) was knocked out in NIC mice [179], by genetic crossing of NIC mice with Stk11 flfl mice, to generate $S t k 11^{-/-} \mathrm{NIC}\left(L k b 1^{-/-} \mathrm{NIC}\right)$ mice. The loss of $L k b 1$ reduced the latency of tumorigenesis in $L k b 1^{-/-}$NIC mice compared with NIC mice [77]. Furthermore, tumors from $L k b 1^{-/-}$NIC mice showed enhanced phosphorylation of the S6K1 substrate ribosomal protein (S6), elevated ATP levels, and changes in metabolic enzymes and metabolites indicative of mTORC1 hyperactivation (Figure 2) [77]. Chen et al. [180] assessed the role of LKB1 in breast cancer, including HER2-positive breast cancers, using immunohistochemical analysis of tumors from early breast cancer patients and in silico analysis obtained from the Molecular Taxonomy of Breast Cancer International Consortium (METABRIC) dataset. Although LKB1 protein expression did not correlate with HER2 status, high LKB1 expression in HER2-positive breast cancer patients correlated with improved overall survival, consistent with the findings of Andrade-Vieira et al. [77] that found NIC mice expressing LKB1 had an increased tumor latency compared to $L k b 1^{-/-} \mathrm{NIC}$ mice. 


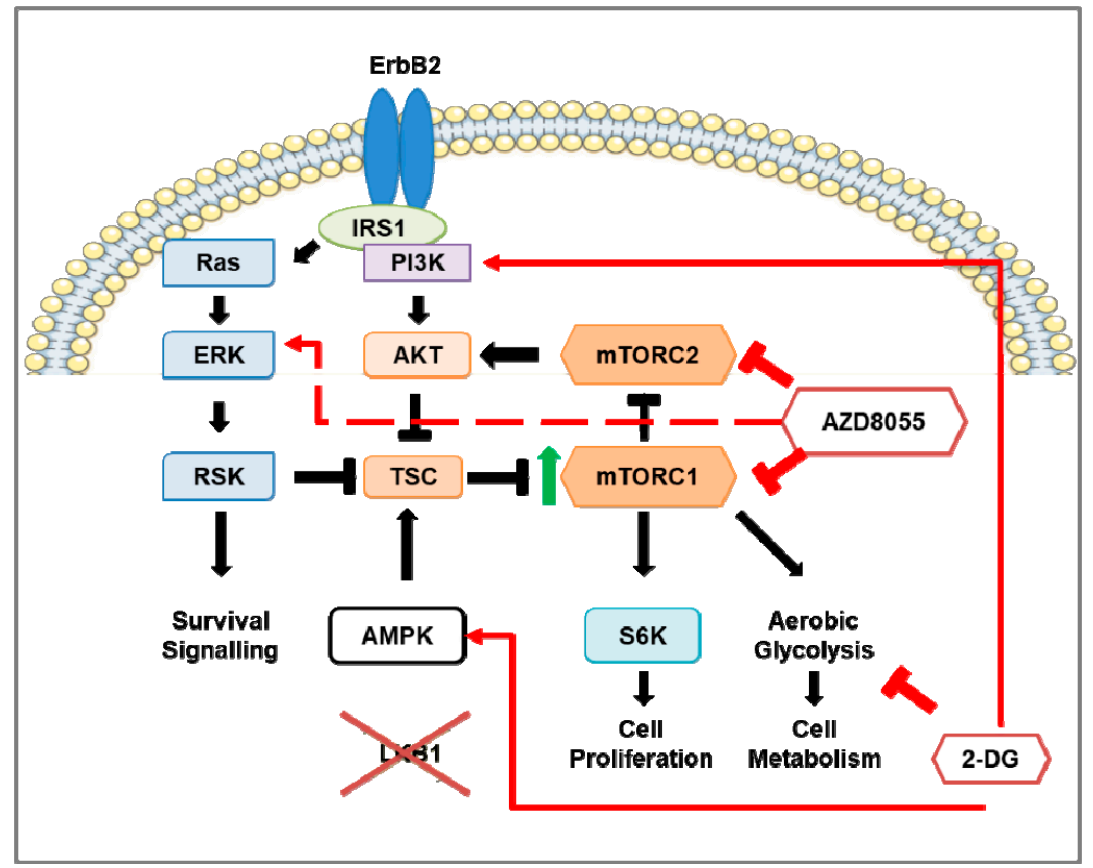

Figure 2. The effects of mTOR and inhibition of mTOR and aerobic glycolysis in $S t k 11^{-/-}$NIC (Lkb1 ${ }^{-/-}$NIC) mouse model of HER2-positive breast cancer. The overexpression of ErbB2 in the breast tumors of the HER2-positive breast cancer mouse model (NIC) shows up-regulation of ERK, Akt, and mTOR signaling as well as aerobic glycolysis; however, deficiency of LKB1 expression in NIC mice ( $L k b 1^{-/-}$NIC) leads to hyperactivation of mTOR (indicated by the green arrow) that enhances aerobic glycolysis. In $L k b 1^{-/-}$NIC mammary gland tumors, inhibition of mTORC1 and mTORC2 via AZD8055 prevents mTORC1-dependent phosphorylation of S6K and mTORC2-dependent Akt phosphorylation on S473, inhibits cell proliferation, and reduces aerobic glycolysis through downregulation of glycolytic enzymes. Prolonged inhibition of mTOR activates pro-survival pathways in a pERK-p90RSK-dependent manner (indicated by the red, dashed arrow). In addition, inhibition of aerobic glycolysis via 2-deoxy-D-glucose (2-DG) does not affect mTOR activity but promotes activation of AMPK and PI3K. The addition of 2-DG to AZD8055 treatment prevented the AZD8055 induction of ERK activation.

Using the mammary epithelial cells (MECs) of tumors isolated from both from $L k b 1^{-1-}$ NIC and NIC mice, treatments using mTOR inhibitors (rapamycin, Torin-1, and AZD8055) reduced phosphorylation of S6; however, Torin-1 and AZD8055 reduced the levels of phosphorylated Akt on both S473 and T308 (Figure 2) [77], indicating both mTORC1 and mTORC2 were inhibited. Both NVP-BEZ235 and AZD8055 treatments of $L k b 1^{-1-}$ NIC mice reduced the tumor volume compared with the vehicle control, though AZD8055 treatment inhibited the tumor volume significantly more compared with NVP-BEZ235 treatment [151]. When considering mitochondrial function, AZD8055 treatment reduced the mitochondrial content of primary mammary tumors isolated from $L k b 1^{-1-}$ NIC mice, but not in mammary epithelial cells isolated from control wild-type female littermates. Tumors isolated from AZD8055-treated $\mathrm{Lkb1}^{-/}$NIC mice showed significantly reduced expression of glycolytic enzymes (hexokinase 2, lactate dehydrogenase (LDH), and pyruvate dehydrogenase (PDH)) and phosphorylation of 56 compared with the vehicle control. However, tumors from AZD8055-treated mice also showed strong induction of ERK and p90RSK phosphorylation (Figure 2). This activation of the MAPK/ERK pathway is indicative of a pro-survival feedback loop often observed with mTOR inhibition that can contribute to cancer recurrence [151] (reviewed in [181]). 


\section{Glycolysis in Breast Cancer}

\subsection{Glycolysis and Oxidative Phosphorylation}

Glycolysis uses glucose to generate two molecules of pyruvate and energy in the form of ATP (Figure 3) [182] (reviewed in [183]). Under aerobic conditions, pyruvate is transported into the mitochondria and converted to citrate and $\mathrm{CO}_{2}$. Citrate goes on to the tricarboxylic acid (TCA) cycle that facilitates the transport of electrons to the electron transport chain (ETC). Electrons generated by the ETC are used for oxidative phosphorylation (OXPHOS) to generate 36 ATP molecules per glucose molecule (reviewed in [184]). When oxygen is limited, pyruvate is metabolized via anaerobic glycolysis, which generates ATP less efficiently but 100X more rapidly compared to OXPHOS [185]. In anaerobic glycolysis, $\mathrm{LDH}$ catalyzes the reduction of pyruvate and regeneration of $\mathrm{NAD}^{+}$, where pyruvate and NADH are converted to lactate, $\mathrm{NAD}^{+}$, and two ATP molecules (Figure 3).

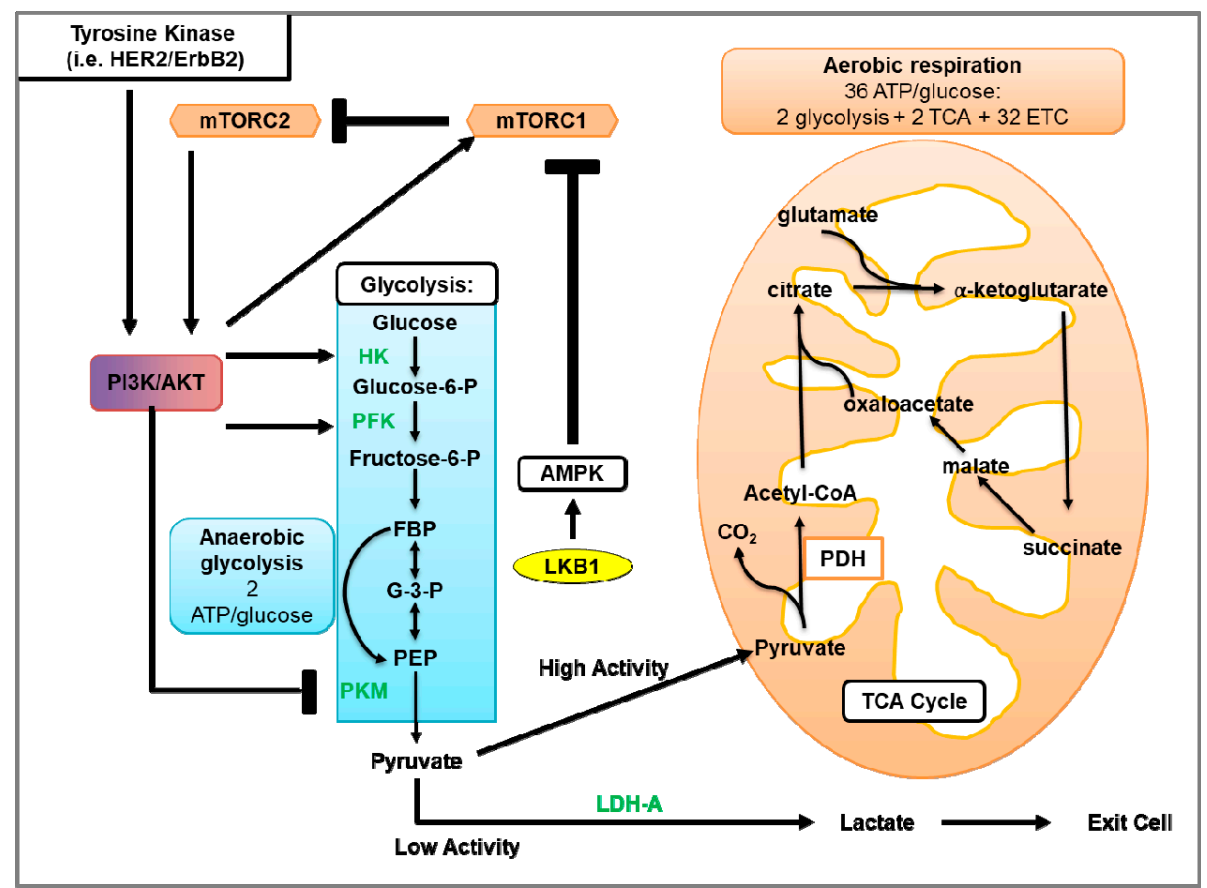

Figure 3. Glycolysis and aerobic respiration. The first phase of glycolysis (blue box) is the destabilization of glucose, resulting in the formation of glucose 6-phosphate (Glucose-6-P), which is further processed to $\beta$-d-Fructose 1,6-bisphosphate (FBP). In the second phase of glycolysis, FBP is converted to glyceraldehyde 3-phosphate (G-3-P). In the final phase of glycolysis, G-3-P undergoes several steps to generate pyruvate and 2 ATP molecules. In the presence of sufficient oxygen, pyruvate is transported into the mitochondria where pyruvate is processed by the tricarboxylic acid (TCA) cycle that transfers electrons to the electron transport chain (ETC) for oxidative phosphorylation, which produces $\sim 36$ molecules of ATP. In contrast, anaerobic or aerobic glycolysis instead uses LDH to facilitate the conversion of pyruvate and NADH to lactate, $\mathrm{NAD}^{+}$, and two ATP molecules. Growth factors mediate glycolytic metabolism through activation of tyrosine kinases (such as HER2/ErbB2) and/or Akt activation. Akt activates glycolytic enzymes such as hexokinase (HK) and phosphofructokinase (PFK). In addition to activating Akt, tyrosine kinases increase the levels of peptides phosphorylated on tyrosine residues. As pyruvate kinases M2 (PKM) binds to phosphotyrosine on peptides, this subsequently results in increased binding of phosphotyrosine peptides to PKM. This binding suppresses the PKM-mediated generation of pyruvate to be used in glycolysis. Furthermore, Akt activates the mTOR pathway, thereby stimulating protein synthesis and up-regulating numerous components of the glycolytic pathway. With low levels of ATP, LKB1-activated AMPK can inhibit mTOR-dependent protein synthesis and the activation of glycolytic genes. 


\subsection{Glycolysis in Cancer}

Warburg et al. [186] made the landmark observation that tumor cells metabolized high levels of glucose to produce ATP and lactate in the presence of oxygen. The metabolic shift of OXPHOS to aerobic glycolysis in tumor cells is known as the "Warburg effect". This established the paradigm that cancer cells use glycolysis instead of OXPHOS to produce ATP due to impaired OXPHOS function, potentially due to mitochondrial damage. However, contrary to the hypotheses postulated since the discovery of the Warburg effect, mitochondria in most tumor cells are intact and OXPHOS is not impaired in most cases [187]. Recent evidence indicates that OXPHOS and aerobic glycolysis do function in cancer cells [188]. Using a population of cancer stem cells (CSC) from epithelial ovarian cancer, Pasto et al. [189] found that the expression of many essential enzymes involved in TCA and ETC were up-regulated (e.g., citrate synthase (CS), isocitrate dehydrogenase (IDH2), ATP5B, HKII, PKM, and PFK) concomitant with the up-regulation of GLUT1 cell surface levels in CSCs $\left(\mathrm{CD} 44^{+} \mathrm{CD} 117^{+}\right)$compared to non-tumorigenic CD44 ${ }^{+} \mathrm{CD} 117^{-}$cells. The CSCs showed characteristics consistent with cells that use OXPHOS such as elevated generation of mitochondrial reactive oxygen species (ROS), increased membrane potential, and ETC inhibition, resulting in apoptosis. Through evaluation of metabolites isolated from three types of $\mathrm{Kras}^{\mathrm{G} 12 \mathrm{D}}$-driven non-small cell lung cancer (NSCLC) mouse models and xenograft models using A549 and H1975 lung cancer cell lines, Davidson et al. [188] observed that the metabolism of lung tumors relied on oxidative metabolism and aerobic glycolysis. Tumors from NSCLC mice showed increased glucose uptake concomitant with increased TCA cycle metabolism. Increases in the levels of lactate were observed in lung tumors of two of the three NSCLC models and the tumors of xenograft mice relative to normal tissues. Furthermore, tumor growth rates differed between the lung tumors from the two NSCLC models, although they both showed high levels of lactate, which argues that lactate levels do not necessarily correlate with proliferation. Interestingly, lung tumor cells isolated from one of the NSCLC mouse models relied more on glutamine metabolism to support cell growth, whereas tumor cells analyzed directly from the same NSCLC mouse model did not rely on glutamine metabolism. The observation of metabolic differences between lung cancer cells in vitro and in vivo suggested a role of the tumor microenvironment in influencing cancer cell metabolism. Interestingly, OXPHOS supports tumor growth through the metabolites generated by glycolysis and the ETC. For example, the generation of aspartate, a precursor used to synthesize purine and pyrimidine, can be metabolized by tumor cells to support growth $[190,191]$. Moreover, several studies found that the loss of OXPHOS by depletion of mitochondrial DNA (mtDNA) resulted in reduced tumor cell proliferation in vitro and tumorigenicity in vivo [192-194].

Several studies have observed that resistance to targeted therapies in cancer cells is associated with increased glycolytic activity and expression of glycolytic enzymes [195-197]. The concept of metabolic reprogramming has gained popularity as a means for tumors to adapt to the metabolic requirements for survival (for further details, please refer to reviews $[198,199])$.

\subsection{Glycolysis in HER2-Positive Breast Cancer and the Involvement of mTOR}

HER2 overexpression in breast cancer cell lines increased glycolysis as indicated by increased glucose uptake and lactate production, and decreased oxygen consumption rates [200]. Zhao et al. [200] found that HER2 overexpression in breast cancer cell lines MCF-7 and MDA-MB-435 increased glycolysis, indicated by increased glucose uptake and lactate production, and decreased oxygen consumption rates. Of the HER2-positive breast cancer subtypes, metabolomics data of patient tumors showed that the HER2-E and basal-like subtypes had elevated levels of glycolytic enzymes G-6-P and F-6-P and lactate compared to the luminal A and luminal B subtypes [201]. Zhang et al. [202] recently identified that the DNA repair protein Transcriptional repressor zinc finger and BTB domain containing 1 (ZBTB1) was dramatically down-regulated in breast tumors of HER2-positive patients, and that ZBTB1 suppressed HER2 expression by binding to the 
estrogen receptor alpha $(E R \alpha)$ binding site of the HER2 intron. Re-expression of ZBTB1 in HER2-expressing breast cancer cell lines reduced lactate production, glucose uptake, and down-regulated LDH and HK expression, indicating that the elevated expression of HER2 due to the loss of ZBTB1 promotes aerobic glycolysis [195]. Interestingly, Gale et al. [203] observed a metabolic shift in HER2-positive cell lines that acquired trastuzumab resistance. Here, trastuzumab-resistant, HER2-positive cells showed an up-regulation of numerous genes encoding enzymes involved in OXPHOS. Although the oxygen consumption rate was similar among parental HER2-positive cell lines and trastuzumab-resistance cells, lactate production was not examined. Trastuzumab-resistant cells and patient data showed increased expression of the ATP synthase subunits ATP5J and ATP5B, which were also found to correlate with poor survival. The addition of an ATP synthase inhibitor resensitized tumor cells to trastuzumab in xenograft mouse models of HER2-positive breast cancer. In contrast, studies have observed increased glycolysis, via increased glucose uptake and lactate production, in trastuzumab-resistant, HER2-positive breast cancer cells in vitro and in vivo using xenograft mouse models [195,204]. Aberrant activation of Akt, which is activation by HER2, has been observed to increase glucose consumption and lactate production, indicative of aerobic glycolysis in cancer cells [205]. Using murinederived leukemic and human glioblastoma cell lines and xenograft mouse models, Elstrom et al. [170] demonstrated that overexpression and activation of Akt stimulated aerobic glycolysis as indicated by the increase in glucose consumption and lactate production. This effect was negated by treatment with the Akt inhibitor LY294002 in vitro $[205,206]$ and in vivo [205]. The glycolytic activities in HER2-positive breast cancer cell lines are reduced in response to trastuzumab treatment. Together, these studies indicate that activation of the HER2-Akt pathway enhances glycolytic activity. Constitutive activation of mTORC1 was also shown to promote glycolysis. Loss of NPRL2, a negative regulator of mTORC1, decreased the levels of TCA metabolites and was concomitant with increases in glucose uptake and lactate production [207]. This suggests that mTOR hyperactivation is a critical contributor to the elevated glycolytic activity observed in HER2-positive breast cancer.

As the HER2-E subtype expresses higher levels of HER2 and glycolytic metabolites compared with other HER2-positive breast cancer subtypes, the HER2-E subtype also displayed higher levels of phosphorylated S6K, a substrate of mTORC1 [208]. Likewise, since the loss of $L k b 1$ causes mTORC1 hyperactivation, tumors from the $L k b 1^{-/-} \mathrm{NIC}$ mouse model of HER2-positive mammary cancer showed elevated levels of glycolytic metabolites, including lactate, and up-regulated LDH and PDH expression compared with control wildtype (WT) mice [77]. Inhibition of mTORC1/mTORC2 (Torin-1, AZD8055) or mTORC1 (rapamycin) down-regulated LDH expression and had little to no effect on PDH expression in the primary tumor cells isolated from $L k b 1^{-/}$NIC mice compared to the cells from NIC mice [77,151]. Furthermore, tumors from AZD8055-treated $L k b 1^{-/-}$NIC mice showed reduced glycolytic activity and oxygen consumption rates compared with vehicle-treated mice. Characterization of mitochondrial content, size, and cristae density was greater in mammary tumors from $\mathrm{Lkb1}^{-/}$NIC mice compared with mammary glands from control WT mice. AZD8055 treatment reduced the mitochondrial content in $L k b 1^{-1-}$ NIC but not in control WT mice, indicating the role of mTOR activity in mitochondrial biogenesis in HER2positive cancer [151]. This study demonstrates that therapies that simultaneously target mTORC1/mTORC2 and glycolytic metabolism in cancer produce the best therapeutic outcome against HER2-positive breast cancer.

\subsection{Glucose Analogs and the Effect on Cancer Cells}

Tumor cells can develop a dependency on glycolysis for survival. Glucose analogs cause glucose deprivation, resulting in the suppression of glycolysis as they cannot be metabolized by cells. 2-deoxy-D-glucose (2-DG) is a glucose analog that is taken into the cytosol through glucose transporters (GLUTs), where hexokinase phosphorylates 2-DG to generate 2-DG-P; however, phosphohexose isomerase is not able to metabolize 2-DG-P any further (reviewed in [209]). Here, downstream glycolysis and production of cellular 
ATP are inhibited by the accumulation of 2-DG, which is associated with impaired cell cycle progression and enhanced cell death of tumor cells [210]. Although 2-DG negatively affects cell cycle progression, studies have demonstrated that the inhibition of glycolysis by 2-DG monotherapy is concomitant with the induction of Akt phosphorylation at T308 and S473 [211,212]. This could have negative implications in the efficacy of 2-DG as a cancer treatment as 2-DG-induced Akt activation would oppose the 2-DG-dependent inhibition of cell proliferation and survival.

Considering that the availability of endogenous glucose can mitigate the efficacy of 2-DG, 2-DG may not completely block glycolysis. However, antiproliferative and cell deathpromoting effects of 2-DG have been observed in vitro and in vivo in cancer cells [213]. Treatment using 2-DG induces endoplasmic reticulum stress, leading to autophagy. This results from the accumulation of misfolded proteins in the ER lumen concomitant with ER stress and the unfolded protein response, a mechanism of inhibiting protein translation to relieve ER stress [213]. Inhibition of autophagy prevented 2-DG-induced autophagy and ER stress but did not reverse the depletion of ATP. Furthermore, treatment using oxamate, which depletes ATP without inducing ER stress, did not induce autophagy [213], indicating that 2-DG induces autophagy in cancer cells by increasing ER stress and not by ATP depletion.

Suppression of glycolysis in HER2-positive breast cancer has been observed to reduce HER2-driven mammary tumor cell growth in vitro as well as in vivo with mouse models [214]. In the $L k b 1^{-/-}$NIC mouse model of HER2-positive mammary cancer, 2-DG monotherapy reduced tumor burden and growth compared with vehicle-treated mice, but to a lesser extent than AZD8055 monotherapy [151]. Tumors from 2-DG-treated mice showed reduced glycolysis, oxygen consumption rate, mitochondrial content, and down-regulation of HK, PDH, and LDH expression. The combination of AZD8055 and 2-DG further augmented these effects, indicating that 2-DG sensitized the tumor cells to mTORC1/2 inhibition. In addition, 2-DG treatment did not significantly affect the phosphorylation status of S6, ACC, AMPK, p90RSK, and ERK compared to vehicle-treated mice. Interestingly, 2-DG induced phosphorylation of AMPK (T172) concomitant with reduced mTORC1 activity as observed from reduced phosphorylation of mTOR (S2448) and S6K1 (T389) in various cell types (Figure 1) [215]. Hurley et al. reported that 2-DG induced the phosphorylation of AMPK and ACC in HeLa cells that were $\mathrm{LKB}^{+/+}$or $\mathrm{LKB}^{-/-}$[216], indicating that 2-DG induced another kinase responsible for AMPK phosphorylation and activation independent of LKB1. Inhibition of CaMKK2, which also phosphorylates AMPK on T172, using STO-609 prevented 2-DG-induced AMPK phosphorylation [216,217]. Furthermore, since HeLa cells do not express the CaMKK $\beta$ isoforms 1 and 2 [218], shRNA knockdown of the CaMKK $\beta 3$ isoform, but not the CaMKK $\alpha$ isoform, prevented AMPK phosphorylation by 2-DG. Since 2-DG did not significantly induce AMPK or ACC phosphorylation in tumors from $L k b 1^{-/-}$NIC mice [151], this may suggest CaMKK $\beta 3$ is not active in this model. Together, these studies suggest that, in addition to inhibiting glycolysis directly through inhibition of phosphohexose isomerase activity, 2-DG inhibits mTORC1-mediated promotion of glycolysis.

\subsection{Adverse Effects of 2-DG}

Studies assessing the efficacy of 2-DG and other metabolic interventions in combination with various anticancer therapies have observed tolerable adverse effects from the addition of 2-DG [219] (reviewed in [220]). Preclinical studies determined that high dosages negatively impacted the respiratory frequency and mean arterial blood pressure [221], and reversible cardiac toxicity has been associated with 2-DG treatment in rats [222]. Despite the therapeutic potential of 2-DG for cancer treatment, studies have shown little to no effect of 2-DG treatment alone in inhibiting tumor growth in preclinical mice models, including genetic [151] and xenograft models [223]. In a clinical trial conducted in patients with a variety of solid tumors, Raez et al. [219] observed that patients treated with 2-DG pre- 
sented with reversible hyperglycemia (100\%), gastrointestinal bleeding $(6 \%)$, and cardiac abnormalities (QTc prolongation; 22\%).

\subsection{Combination Therapy of mTOR Inhibition and 2-DG in HER2-Positive Breast Cancer Mouse Models}

As previously discussed, HER2 hyperactivity promotes mTOR pathway-dependent up-regulation of glycolytic enzymes, indicating that mTOR is a major contributor to the enhanced glycolytic activation observed in HER2-positive breast cancer. Inhibition of the mTOR pathway can negate the effect of HER2 hyperactivity, enhancing glycolysis in cancer cells, but prolonged inhibition of mTOR pathway activity leads to an up-regulation of ERK activation [111,147]. Consistent with this, our laboratory observed an up-regulation of ERK phosphorylation, concomitant with a decrease in glycolytic activity and tumor growth, in mammary tumors from $L k b 1^{-1-}$ NIC mice treated with the mTORC1/2 inhibitor AZD8055 [151]. Furthermore, mammary tumors from AZD8055-treated mice showed upregulation of AMP, ACC, and p90RSK phosphorylation. Like mTOR inhibition, 2-DG also suppresses glycolysis but activates PI3K [211,212] and AMPK [216,217]. In our preclinical study, 2-DG reduced tumor growth to a lesser extent than AZD8055. As AZD8055 did not completely block glycolytic activity in mammary tumors of $L k b 1^{-1-}$ NIC mice, combination treatment was performed by adding 2-DG to the AZD8055 treatment to further inhibit glycolysis in addition to mTORC1/2. This combination treatment further reduced the mammary tumor volume and burden compared to AZD8055 or 2-DG monotherapies, but more importantly, the addition of 2-DG blocked the AZD8055-dependent induction of ERK phosphorylation, as well as the phosphorylation of AMPK, ACC, and p90RSK [151]. Sun et al. [224] also observed that 2-DG treatment of lung cancer cells resulted in a time- and dose-dependent down-regulation of ERK phosphorylation in an LKB1/AMPK-dependent manner. Although our mouse model lacks LKB1 expression, 2-DG can induce AMPK independently of LKB1, as previously discussed in Section 4.4 of this review. These studies demonstrate the benefit of combining glycolytic inhibition via 2-DG with mTORC1/2 inhibition, in which the addition of 2-DG prevents the mTOR inhibitor-dependent induction of pro-survival MAPK pathway signaling. Furthermore, Cheng et al. showed 2-DG sensitized 5-fluorouracil (5-Fu)-resistant pancreatic cancer cell lines to the cytotoxic effects of 5-Fu [225]. They revealed that 2-DG-mediated activation of PI3K-Akt was required to sensitize the drug-resistant cells to cell growth inhibition and apoptosis induced by 5-Fu. In the study by Ma et al. [226], 2-DG was also found to overcome chemo-resistance due, in part, to the suppression of ATP-dependent drug efflux transporters. These studies strongly suggest that the addition of 2-DG may improve the efficacy of therapies using mTOR inhibition, as well as other targeted therapies, by migrating factors that contribute to drug resistance such as activation of pro-survival signaling and drug efflux.

\section{Concluding Remarks}

The progression and recurrence of HER2-positive breast cancer are supported by HER2-Akt-mTOR signaling that promotes pro-survival signaling and cell cycle progression. Additionally, the mTOR pathway in HER2-positive breast cancer mediates a metabolic shift from glycolysis to OXPHOS to further facilitate the nutrients required for tumor growth. Monotherapeutic inhibition of these signaling pathways has had modest clinical benefits, but combination therapies using mTOR and/or glycolytic inhibition show encouraging outcomes. Other combination therapies showing promising results include the use of cyclin-dependent kinase 4/6 (CDK4/6) inhibitors that block cell progression and mTORC1 activity [227]. This is particularly relevant in the HER2-E subtype that displays DNA amplification of cyclin D1 and CDK4 [208]. Even still, the combination of CDK4/6 and HER2 inhibitors is met with the development of drug resistance in HER2-positive breast cancer treatment [228]. Consistent with this, findings from Finn et al. also indicated that the non-luminal subtypes of HER2-positive breast cancer are more resistant to the beneficial effects of the CDK4/ 6 inhibitor palbociclib [229]; however, this drug has been associated with various dermatological toxicities such as alopecia (reviewed in [230]). Understanding 
the relationship between the HER2-Akt-mTOR pathway, glycolysis, and CDK4/6 may pave the way for improved therapies to treat HER2-positive breast cancer and overcome drug resistance.

Author Contributions: Writing—original draft preparation, R.W.H., P.A.M.; writing-review and editing, R.W.H., P.A.M.; supervision, P.A.M.; project administration, P.A.M.; funding acquisition, P.A.M. Both authors have read and agreed to the published version of the manuscript.

Funding: The authors acknowledge funding support from the Dalhousie Medical Research Foundation and the Breast Cancer Society of Canada.

Acknowledgments: The authors would like to thank members of the Marignani Lab for their support. The authors acknowledge that Dalhousie University campuses are located on original lands of the Mi'kma'ki, the ancestral and unceded territory of the Mi'kmaq People.

Conflicts of Interest: The authors declare no conflict of interest.

\section{References}

1. DeSantis, C.; Ma, J.; Bryan, L.; Jemal, A. Breast cancer statistics, 2013. CA Cancer J. Clin. 2014, 64, 52-62. [CrossRef]

2. Torre, L.A.; Bray, F.; Siegel, R.L.; Ferlay, J.; Lortet-Tieulent, J.; Jemal, A. Global cancer statistics, 2012. CA Cancer J. Clin. 2015, 65, 87-108. [CrossRef]

3. Hu, K.; Ding, P.; Wu, Y.; Tian, W.; Pan, T.; Zhang, S. Global patterns and trends in the breast cancer incidence and mortality according to sociodemographic indices: An observational study based on the global burden of diseases. BMJ Open 2019, 9, e028461. [CrossRef]

4. Chatenoud, L.; Bertuccio, P.; Bosetti, C.; Malvezzi, M.; Levi, F.; Negri, E.; La Vecchia, C. Trends in mortality from major cancers in the Americas: 1980-2010. Ann.Oncol. 2014, 25, 1843-1853. [CrossRef]

5. Anderson, B.O.; Cazap, E.; El Saghir, N.S.; Yip, C.-H.; Khaled, H.M.; Otero, I.V.; Adebamowo, C.A.; Badwe, R.A.; Harford, J.B. Optimisation of breast cancer management in low-resource and middle-resource countries: Executive summary of the Breast Health Global Initiative consensus, 2010. Lancet Oncol. 2011, 12, 387-398. [CrossRef]

6. $\quad$ Li, N.; Deng, Y.; Zhou, L.; Tian, T.; Yang, S.; Wu, Y.; Zheng, Y.; Zhai, Z.; Hao, Q.; Song, D.; et al. Global burden of breast cancer and attributable risk factors in 195 countries and territories, from 1990 to 2017: Results from the Global Burden of Disease Study 2017. J. Hematol. Oncol. 2019, 12, 140. [CrossRef]

7. Moasser, M.M.; Krop, I.E. The Evolving Landscape of HER2 Targeting in Breast Cancer. JAMA Oncol. 2015, 1, $1154-1161$. [CrossRef]

8. Tzahar, E.; Waterman, H.; Chen, X.; Levkowitz, G.; Karunagaran, D.; Lavi, S.; Ratzkin, B.J.; Yarden, Y. A hierarchical network of interreceptor interactions determines signal transduction by Neu differentiation factor/neuregulin and epidermal growth factor. Mol. Cell Biol.J. 1996, 16, 5276-5287. [CrossRef]

9. Olayioye, M.A.; Neve, R.M.; Lane, H.A.; Hynes, N.E. The ErbB signaling network: Receptor heterodimerization in development and cancer. $E M B O J .2000,19,3159-3167$. [CrossRef]

10. Parker, J.S.; Mullins, M.; Cheang, M.C.U.; Leung, S.; Voduc, D.; Vickery, T.; Davies, S.; Fauron, C.; He, X.; Hu, Z.; et al. Supervised risk predictor of breast cancer based on intrinsic subtypes. J. Clin. Oncol. 2009, 27, 1160-1167. [CrossRef]

11. Sørlie, T.; Perou, C.M.; Tibshirani, R.; Aas, T.; Geisler, S.; Johnsen, H.; Hastie, T.; Eisen, M.B.; van de Rijn, M.; Jeffrey, S.S.; et al. Gene expression patterns of breast carcinomas distinguish tumor subclasses with clinical implications. Proc. Natl. Acad. Sci. USA 2001, 98, 10869-10874. [CrossRef]

12. Llombart-Cussac, A.; Cortés, J.; Paré, L.; Galván, P.; Bermejo, B.; Martínez, N.; Vidal, M.; Pernas, S.; López, R.; Muñoz, M.; et al. HER2-enriched subtype as a predictor of pathological complete response following trastuzumab and lapatinib without chemotherapy in early-stage HER2-positive breast cancer (PAMELA): An open-label, single-group, multicentre, phase 2 trial. Lancet Oncol. 2017, 18, 545-554. [CrossRef]

13. Prat, A.; Pascual, T.; Adamo, B. Intrinsic molecular subtypes of HER2+ breast cancer. Oncotarget 2017, 8, 73362-73363. [CrossRef]

14. Gajria, D.; Chandarlapaty, S. HER2-amplified breast cancer: Mechanisms of trastuzumab resistance and novel targeted therapies. Expert Rev. Anticancer Ther. 2011, 11, 263-275. [CrossRef] [PubMed]

15. Slamon, D.J.; Clark, G.M.; Wong, S.G.; Levin, W.J.; Ullrich, A.; McGuire, W.L. Human breast cancer: Correlation of relapse and survival with amplification of the HER-2/neu oncogene. Science 1987, 235, 177. [CrossRef] [PubMed]

16. Loibl, S.; Gianni, L. HER2-positive breast cancer. Lancet 2017, 389, 2415-2429. [CrossRef]

17. Sabatini, D.M. Twenty-five years of mTOR: Uncovering the link from nutrients to growth. Proc. Natl. Acad. Sci. USA 2017, 114, 11818-11825. [CrossRef] [PubMed]

18. Fadaka, A.; Ajiboye, B.; Ojo, O.; Adewale, O.; Olayide, I.; Emuowhochere, R. Biology of glucose metabolization in cancer cells. J. Oncol. Sci. 2017, 3, 45-51. [CrossRef]

19. Yarden, Y.; Sliwkowski, M.X. Untangling the ErbB signalling network. Nat. Rev. Mol. Cell Biol. 2001, 2, 127-137. [CrossRef] [PubMed] 
20. Yarden, Y. The EGFR family and its ligands in human cancer: Signalling mechanisms and therapeutic opportunities. Eur. J. Cancer 2001, 37, 3-8. [CrossRef]

21. Klapper, L.N.; Glathe, S.; Vaisman, N.; Hynes, N.E.; Andrews, G.C.; Sela, M.; Yarden, Y. The ErbB-2/HER2 oncoprotein of human carcinomas may function solely as a shared coreceptor for multiple stroma-derived growth factors. Proc. Natl. Acad. Sci. USA 1999, 96, 4995-5000. [CrossRef]

22. Järvinen, T.A.; Kononen, J.; Pelto-Huikko, M.; Isola, J. Expression of topoisomerase IIalpha is associated with rapid cell proliferation, aneuploidy, and c-erbB2 overexpression in breast cancer. Am. J. Pathol. 1996, 148, 2073-2082.

23. Ross, J.S.; Fletcher, J.A. The HER-2/neu Oncogene in Breast Cancer: Prognostic Factor, Predictive Factor, and Target for Therapy. STEM CELLS 1998, 16, 413-428. [CrossRef] [PubMed]

24. Graus-Porta, D.; Beerli, R.R.; Daly, J.M.; Hynes, N.E. ErbB-2, the preferred heterodimerization partner of all ErbB receptors, is a mediator of lateral signaling. EMBO J. 1997, 16, 1647-1655. [CrossRef] [PubMed]

25. Levkowitz, G.; Waterman, H.; Zamir, E.; Kam, Z.; Oved, S.; Langdon, W.Y.; Beguinot, L.; Geiger, B.; Yarden, Y. c-Cbl/Sli-1 regulates endocytic sorting and ubiquitination of the epidermal growth factor receptor. Genes Dev. 1998, 12, 3663-3674. [CrossRef] [PubMed]

26. Jansen, M.; ten Klooster, J.P.; Offerhaus, G.J.; Clevers, H. LKB1 and AMPK Family Signaling: The Intimate Link Between Cell Polarity and Energy Metabolism. Physiol. Rev. 2009, 89, 777-798. [CrossRef]

27. Klapper, L.N.; Waterman, H.; Sela, M.; Yarden, Y. Tumor-inhibitory Antibodies to HER-2/ErbB-2 May Act by Recruiting c-Cbl and Enhancing Ubiquitination of HER-2. Cancer Res. 2000, 60, 3384.

28. FDA. Drugs@FDA: FDA-Approved Drugs. Available online: https://www.accessdata.fda.gov/scripts/cder/daf/index.cfm? event=reportsSearch.process (accessed on 1 March 2021).

29. Maadi, H.; Nami, B.; Tong, J.; Li, G.; Wang, Z. The effects of trastuzumab on HER2-mediated cell signaling in CHO cells expressing human HER2. BMC Cancer 2018, 18, 238. [CrossRef]

30. Park, S.; Jiang, Z.; Mortenson, E.D.; Deng, L.; Radkevich-Brown, O.; Yang, X.; Sattar, H.; Wang, Y.; Brown, N.K.; Greene, M.; et al. The therapeutic effect of anti-HER2/neu antibody depends on both innate and adaptive immunity. Cancer Cell 2010, 18, 160-170. [CrossRef]

31. Klapper, L.N.; Vaisman, N.; Hurwitz, E.; Pinkas-Kramarski, R.; Yarden, Y.; Sela, M. A subclass of tumor-inhibitory monoclonal antibodies to ErbB-2/HER2 blocks crosstalk with growth factor receptors. Oncogene 1997, 14, 2099-2109. [CrossRef]

32. Baselga, J.; Tripathy, D.; Mendelsohn, J.; Baughman, S.; Benz, C.C.; Dantis, L.; Sklarin, N.T.; Seidman, A.D.; Hudis, C.A.; Moore, J.; et al. Phase II study of weekly intravenous trastuzumab (Herceptin) in patients with HER2/neu-overexpressing metastatic breast cancer. Semin. Oncol. 1999, 26, 78-83. [PubMed]

33. Pegram, M.D.; Pienkowski, T.; Northfelt, D.W.; Eiermann, W.; Patel, R.; Fumoleau, P.; Quan, E.; Crown, J.; Toppmeyer, D.; Smylie, M.; et al. Results of Two Open-Label, Multicenter Phase II Studies of Docetaxel, Platinum Salts, and Trastuzumab in HER2-Positive Advanced Breast Cancer. JNCI J. Natl. Cancer Inst. 2004, 96, 759-769. [CrossRef] [PubMed]

34. Li, H.; Shao, B.; Yan, Y.; Song, G.; Liu, X.; Wang, J.; Liang, X. Efficacy and safety of trastuzumab combined with chemotherapy for first-line treatment and beyond progression of HER2-overexpressing advanced breast cancer. Chin. J. Cancer Res. 2016, 28, 330-338. [CrossRef] [PubMed]

35. Chumsri, S.; Li, Z.; Serie, D.J.; Mashadi-Hossein, A.; Colon-Otero, G.; Song, N.; Pogue-Geile, K.L.; Gavin, P.G.; Paik, S.; MorenoAspitia, A.; et al. Incidence of Late Relapses in Patients With HER2-Positive Breast Cancer Receiving Adjuvant Trastuzumab: Combined Analysis of NCCTG N9831 (Alliance) and NRG Oncology/NSABP B-31. J. Clin. Oncol. 2019, 37, 3425-3435. [CrossRef]

36. Baker, J.H.E.; Kyle, A.H.; Reinsberg, S.A.; Moosvi, F.; Patrick, H.M.; Cran, J.; Saatchi, K.; Häfeli, U.; Minchinton, A.I. Heterogeneous distribution of trastuzumab in HER2-positive xenografts and metastases: Role of the tumor microenvironment. Clin. Exp. Metastasis 2018, 35, 691-705. [CrossRef]

37. Slamon, D.J.; Leyland-Jones, B.; Shak, S.; Fuchs, H.; Paton, V.; Bajamonde, A.; Fleming, T.; Eiermann, W.; Wolter, J.; Pegram, M.; et al. Use of Chemotherapy plus a Monoclonal Antibody against HER2 for Metastatic Breast Cancer That Overexpresses HER2. N. Engl. J. Med. 2001, 344, 783-792. [CrossRef]

38. Seidman, A.; Hudis, C.; Pierri, M.K.; Shak, S.; Paton, V.; Ashby, M.; Murphy, M.; Stewart, S.J.; Keefe, D. Cardiac Dysfunction in the Trastuzumab Clinical Trials Experience. J. Clin. Oncol. 2002, 20, 1215-1221. [CrossRef]

39. Crone, S.A.; Zhao, Y.-Y.; Fan, L.; Gu, Y.; Minamisawa, S.; Liu, Y.; Peterson, K.L.; Chen, J.; Kahn, R.; Condorelli, G.; et al. ErbB2 is essential in the prevention of dilated cardiomyopathy. Nat. Med. 2002, 8, 459-465. [CrossRef]

40. Ozcelik, C.; Erdmann, B.; Pilz, B.; Wettschureck, N.; Britsch, S.; Hübner, N.; Chien, K.R.; Birchmeier, C.; Garratt, A.N. Conditional mutation of the ErbB2 (HER2) receptor in cardiomyocytes leads to dilated cardiomyopathy. Proc. Natl. Acad. Sci. USA 2002, 99, 8880-8885. [CrossRef]

41. Gomez, H.L.; Doval, D.C.; Chavez, M.A.; Ang, P.C.S.; Aziz, Z.; Nag, S.; Ng, C.; Franco, S.X.; Chow, L.W.C.; Arbushites, M.C.; et al. Efficacy and Safety of Lapatinib As First-Line Therapy for ErbB2-Amplified Locally Advanced or Metastatic Breast Cancer. J. Clin. Oncol. 2008, 26, 2999-3005. [CrossRef]

42. Geyer, C.E.; Forster, J.; Lindquist, D.; Chan, S.; Romieu, C.G.; Pienkowski, T.; Jagiello-Gruszfeld, A.; Crown, J.; Chan, A.; Kaufman, B.; et al. Lapatinib plus Capecitabine for HER2-Positive Advanced Breast Cancer. N. Engl. J. Med. 2006, 355, 2733-2743. [CrossRef] [PubMed] 
43. Cameron, D.; Casey, M.; Oliva, C.; Newstat, B.; Imwalle, B.; Geyer, C.E. Lapatinib plus capecitabine in women with HER-2-positive advanced breast cancer: Final survival analysis of a phase III randomized trial. Oncologist 2010, 15, 924-934. [CrossRef] [PubMed]

44. Cameron, D.; Casey, M.; Press, M.; Lindquist, D.; Pienkowski, T.; Romieu, C.G.; Chan, S.; Jagiello-Gruszfeld, A.; Kaufman, B.; Crown, J.; et al. A phase III randomized comparison of lapatinib plus capecitabine versus capecitabine alone in women with advanced breast cancer that has progressed on trastuzumab: Updated efficacy and biomarker analyses. Breast Cancer Res. Treat. 2008, 112, 533-543. [CrossRef]

45. Labonte, M.J.; Wilson, P.M.; Yang, D.; Zhang, W.; Ladner, R.D.; Ning, Y.; Gerger, A.; Bohanes, P.O.; Benhaim, L.; El-Khoueiry, R.; et al. The Cyclin D1 (CCND1) A870G polymorphism predicts clinical outcome to lapatinib and capecitabine in HER2-positive metastatic breast cancer. Ann. Oncol. 2012, 23, 1455-1464. [CrossRef]

46. Burstein, H.J.; Sun, Y.; Dirix, L.Y.; Jiang, Z.; Paridaens, R.; Tan, A.R.; Awada, A.; Ranade, A.; Jiao, S.; Schwartz, G.; et al. Neratinib, an Irreversible ErbB Receptor Tyrosine Kinase Inhibitor, in Patients With Advanced ErbB2-Positive Breast Cancer. J. Clin. Oncol. 2010, 28, 1301-1307. [CrossRef]

47. Martin, M.; Bonneterre, J.; Geyer, C.E.; Ito, Y.; Ro, J.; Lang, I.; Kim, S.-B.; Germa, C.; Vermette, J.; Wang, K.; et al. A phase two randomised trial of neratinib monotherapy versus lapatinib plus capecitabine combination therapy in patients with HER2+ advanced breast cancer. Eur. J. Cancer 2013, 49, 3763-3772. [CrossRef]

48. Saura, C.; Oliveira, M.; Feng, Y.-H.; Dai, M.-S.; Chen, S.-W.; Hurvitz, S.A.; Kim, S.-B.; Moy, B.; Delaloge, S.; Gradishar, W.; et al. Neratinib Plus Capecitabine Versus Lapatinib Plus Capecitabine in HER2-Positive Metastatic Breast Cancer Previously Treated With $\geq 2$ HER2-Directed Regimens: Phase III NALA Trial. J. Clin. Oncol. 2020, 38, 3138-3149. [CrossRef] [PubMed]

49. Baselga, J.; Gelmon, K.A.; Verma, S.; Wardley, A.; Conte, P.; Miles, D.; Bianchi, G.; Cortes, J.; McNally, V.A.; Ross, G.A.; et al. Phase II trial of pertuzumab and trastuzumab in patients with human epidermal growth factor receptor 2-positive metastatic breast cancer that progressed during prior trastuzumab therapy. J. Clin. Oncol. 2010, 28, 1138-1144. [CrossRef] [PubMed]

50. Baselga, J.; Cortés, J.; Kim, S.-B.; Im, S.-A.; Hegg, R.; Im, Y.-H.; Roman, L.; Pedrini, J.L.; Pienkowski, T.; Knott, A.; et al. Pertuzumab plus trastuzumab plus docetaxel for metastatic breast cancer. N. Engl. J. Med. 2012, 366, 109-119. [CrossRef]

51. Swain, S.M.; Baselga, J.; Kim, S.-B.; Ro, J.; Semiglazov, V.; Campone, M.; Ciruelos, E.; Ferrero, J.-M.; Schneeweiss, A.; Heeson, S.; et al. Pertuzumab, trastuzumab, and docetaxel in HER2-positive metastatic breast cancer. N. Engl. J. Med. 2015, 372, 724-734. [CrossRef]

52. von Minckwitz, G.; Procter, M.; de Azambuja, E.; Zardavas, D.; Benyunes, M.; Viale, G.; Suter, T.; Arahmani, A.; Rouchet, N.; Clark, E.; et al. Adjuvant Pertuzumab and Trastuzumab in Early HER2-Positive Breast Cancer. N. Engl. J. Med. 2017, 377, 122-131. [CrossRef] [PubMed]

53. Burris, H.A.; Rugo, H.S.; Vukelja, S.J.; Vogel, C.L.; Borson, R.A.; Limentani, S.; Tan-Chiu, E.; Krop, I.E.; Michaelson, R.A.; Girish, S.; et al. Phase II Study of the Antibody Drug Conjugate Trastuzumab-DM1 for the Treatment of Human Epidermal Growth Factor Receptor 2 (HER2) -Positive Breast Cancer After Prior HER2-Directed Therapy. J. Clin. Oncol. 2010, 29, 398-405. [CrossRef] [PubMed]

54. Verma, S.; Miles, D.; Gianni, L.; Krop, I.E.; Welslau, M.; Baselga, J.; Pegram, M.; Oh, D.-Y.; Diéras, V.; Guardino, E.; et al. Trastuzumab emtansine for HER2-positive advanced breast cancer. N. Engl. J. Med. 2012, 367, 1783-1791. [CrossRef]

55. Modi, S.; Saura, C.; Yamashita, T.; Park, Y.H.; Kim, S.-B.; Tamura, K.; Andre, F.; Iwata, H.; Ito, Y.; Tsurutani, J.; et al. Trastuzumab Deruxtecan in Previously Treated HER2-Positive Breast Cancer. N. Engl. J. Med. 2020, 382, 610-621. [CrossRef]

56. Murthy, R.K.; Loi, S.; Okines, A.; Paplomata, E.; Hamilton, E.; Hurvitz, S.A.; Lin, N.U.; Borges, V.; Abramson, V.; Anders, C.; et al. Tucatinib, Trastuzumab, and Capecitabine for HER2-Positive Metastatic Breast Cancer. N. Engl. J. Med. 2019, 382, 597-609. [CrossRef]

57. Ma, F.; Li, Q.; Chen, S.; Zhu, W.; Fan, Y.; Wang, J.; Luo, Y.; Xing, P.; Lan, B.; Li, M.; et al. Phase I Study and Biomarker Analysis of Pyrotinib, a Novel Irreversible Pan-ErbB Receptor Tyrosine Kinase Inhibitor, in Patients with Human Epidermal Growth Factor Receptor 2-Positive Metastatic Breast Cancer. J. Clin. Oncol. 2017, 35, 3105-3112. [CrossRef]

58. Ma, F.; Ouyang, Q.; Li, W.; Jiang, Z.; Tong, Z.; Liu, Y.; Li, H.; Yu, S.; Feng, J.; Wang, S.; et al. Pyrotinib or Lapatinib Combined With Capecitabine in HER2-Positive Metastatic Breast Cancer With Prior Taxanes, Anthracyclines, and/or Trastuzumab: A Randomized, Phase II Study. J. Clin. Oncol. 2019, 37, 2610-2619. [CrossRef]

59. Xu, B.; Zhang, Q.; Sun, T.; Li, W.; Teng, Y.e.; Hu, X.; Bondarenko, I.; Adamchuk, H.; Zhang, L.; Trukhin, D.; et al. Efficacy, Safety, and Immunogenicity of HLX02 Compared with Reference Trastuzumab in Patients with Recurrent or Metastatic HER2-Positive Breast Cancer: A Randomized Phase III Equivalence Trial. BioDrugs 2021. [CrossRef]

60. Rusnak, D.W.; Lackey, K.; Affleck, K.; Wood, E.R.; Alligood, K.J.; Rhodes, N.; Keith, B.R.; Murray, D.M.; Knight, W.B.; Mullin, R.J.; et al. The Effects of the Novel, Reversible Epidermal Growth Factor Receptor/ErbB-2 Tyrosine Kinase Inhibitor, GW2016, on the Growth of Human Normal and Tumor-derived Cell Lines in Vitro and in Vivo. Mol. Cancer Ther. 2001, 1, 85-94.

61. Konecny, G.E.; Pegram, M.D.; Venkatesan, N.; Finn, R.; Yang, G.; Rahmeh, M.; Untch, M.; Rusnak, D.W.; Spehar, G.; Mullin, R.J.; et al. Activity of the Dual Kinase Inhibitor Lapatinib (GW572016) against HER-2-Overexpressing and Trastuzumab-Treated Breast Cancer Cells. Cancer Res. 2006, 66, 1630. [CrossRef] [PubMed]

62. Deblois, G.; Smith, H.W.; Tam, I.S.; Gravel, S.-P.; Caron, M.; Savage, P.; Labbé, D.P.; Bégin, L.R.; Tremblay, M.L.; Park, M.; et al. $\mathrm{ERR} \alpha$ mediates metabolic adaptations driving lapatinib resistance in breast cancer. Nat. Commun. 2016, 7, 12156. [CrossRef] [PubMed] 
63. Rabindran, S.K.; Discafani, C.M.; Rosfjord, E.C.; Baxter, M.; Floyd, M.B.; Golas, J.; Hallett, W.A.; Johnson, B.D.; Nilakantan, R.; Overbeek, E.; et al. Antitumor Activity of HKI-272, an Orally Active, Irreversible Inhibitor of the HER-2 Tyrosine Kinase. Cancer Res. 2004, 64, 3958. [CrossRef] [PubMed]

64. Canonici, A.; Gijsen, M.; Mullooly, M.; Bennett, R.; Bouguern, N.; Pedersen, K.; O’Brien, N.A.; Roxanis, I.; Li, J.-L.; Bridge, E.; et al. Neratinib overcomes trastuzumab resistance in HER2 amplified breast cancer. Oncotarget 2013, 4, 1592-1605. [CrossRef] [PubMed]

65. Sudhan, D.R.; Guerrero-Zotano, A.; Won, H.; González Ericsson, P.; Servetto, A.; Huerta-Rosario, M.; Ye, D.; Lee, K.-m.; Formisano, L.; Guo, Y.; et al. Hyperactivation of TORC1 Drives Resistance to the Pan-HER Tyrosine Kinase Inhibitor Neratinib in HER2-Mutant Cancers. Cancer Cell 2020, 37, 183-199. [CrossRef]

66. Chan, A.; Delaloge, S.; Holmes, F.A.; Moy, B.; Iwata, H.; Harvey, V.J.; Robert, N.J.; Silovski, T.; Gokmen, E.; von Minckwitz, G.; et al. Neratinib after trastuzumab-based adjuvant therapy in patients with HER2-positive breast cancer (ExteNET): A multicentre, randomised, double-blind, placebo-controlled, phase 3 trial. Lancet Oncol. 2016, 17, 367-377. [CrossRef]

67. Tóth, G.; Szöőr, Á.; Simon, L.; Yarden, Y.; Szöllősi, J.; Vereb, G. The combination of trastuzumab and pertuzumab administered at approved doses may delay development of trastuzumab resistance by additively enhancing antibody-dependent cell-mediated cytotoxicity. MAbs 2016, 8, 1361-1370. [CrossRef]

68. Agus, D.B.; Akita, R.W.; Fox, W.D.; Lewis, G.D.; Higgins, B.; Pisacane, P.I.; Lofgren, J.A.; Tindell, C.; Evans, D.P.; Maiese, K.; et al. Targeting ligand-activated ErbB2 signaling inhibits breast and prostate tumor growth. Cancer Cell 2002, 2, 127-137. [CrossRef]

69. Scheuer, W.; Friess, T.; Burtscher, H.; Bossenmaier, B.; Endl, J.; Hasmann, M. Strongly Enhanced Antitumor Activity of Trastuzumab and Pertuzumab Combination Treatment on HER2-Positive Human Xenograft Tumor Models. Cancer Res. 2009, 69, 9330. [CrossRef]

70. Bines, J.; Clark, E.; Barton, C.; Restuccia, E.; Procter, M.; Sonnenblick, A.; Fumagalli, D.; Parlier, D.; Arahmani, A.; Baselga, J.; et al. Patient-reported function, health-related quality of life, and symptoms in APHINITY: Pertuzumab plus trastuzumab and chemotherapy in HER2-positive early breast cancer. Br. J. Cancer 2021. [CrossRef]

71. Ogitani, Y.; Hagihara, K.; Oitate, M.; Naito, H.; Agatsuma, T. Bystander killing effect of DS-8201a, a novel anti-human epidermal growth factor receptor 2 antibody-drug conjugate, in tumors with human epidermal growth factor receptor 2 heterogeneity. Cancer Sci. 2016, 107, 1039-1046. [CrossRef]

72. Ogitani, Y.; Aida, T.; Hagihara, K.; Yamaguchi, J.; Ishii, C.; Harada, N.; Soma, M.; Okamoto, H.; Oitate, M.; Arakawa, S.; et al. DS-8201a, A Novel HER2-Targeting ADC with a Novel DNA Topoisomerase I Inhibitor, Demonstrates a Promising Antitumor Efficacy with Differentiation from T-DM1. Clin. Cancer Res. 2016, 22, 5097. [CrossRef] [PubMed]

73. Kulukian, A.; Lee, P.; Taylor, J.; Rosler, R.; de Vries, P.; Watson, D.; Forero-Torres, A.; Peterson, S. Preclinical Activity of HER2Selective Tyrosine Kinase Inhibitor Tucatinib as a Single Agent or in Combination with Trastuzumab or Docetaxel in Solid Tumor Models. Mol. Cancer Ther. 2020, 19, 976. [CrossRef] [PubMed]

74. Li, X.; Yang, C.; Wan, H.; Zhang, G.; Feng, J.; Zhang, L.; Chen, X.; Zhong, D.; Lou, L.; Tao, W.; et al. Discovery and development of pyrotinib: A novel irreversible EGFR/HER2 dual tyrosine kinase inhibitor with favorable safety profiles for the treatment of breast cancer. Eur. J. Pharm. Sci. 2017, 110, 51-61. [CrossRef]

75. Xie, L.; Zhang, E.; Xu, Y.; Gao, W.; Wang, L.; Xie, M.H.; Qin, P.; Lu, L.; Li, S.; Shen, P.; et al. Demonstrating Analytical Similarity of Trastuzumab Biosimilar HLX02 to Herceptin(®) with a Panel of Sensitive and Orthogonal Methods Including a Novel Fc $\gamma$ RIIIa Affinity Chromatography Technology. BioDrugs 2020, 34, 363-379. [CrossRef]

76. Zhu, X.; Ding, Y.; Yu, Y.; Wang, M.; Zhou, W.; Wang, J.; Zhu, X.; Zhang, H.; Wang, M.; Chai, K.; et al. A Phase 1 randomized study compare the pharmacokinetics, safety and immunogenicity of HLX02 to reference CN- and EU-sourced trastuzumab in healthy subjects. Cancer Chemother. Pharmacol. 2021, 87, 349-359. [CrossRef]

77. Andrade-Vieira, R.; Colp, P.; Xu, Z.; Marignani, P.A. Loss of $l k b 1$ expression reduces the latency of ErbB2-mediated mammary gland tumourigenesis, promoting changes in metabolic pathways. PLoS ONE 2013, 8, e56567. [CrossRef]

78. Paul, M.R.; Pan, T.-c.; Pant, D.K.; Shih, N.N.C.; Chen, Y.; Harvey, K.L.; Solomon, A.; Lieberman, D.; Morrissette, J.J.D.; SoucierErnst, D.; et al. Genomic landscape of metastatic breast cancer identifies preferentially dysregulated pathways and targets. J. Clin. Investig. 2020, 130, 4252-4265. [CrossRef]

79. Saxton, R.A.; Sabatini, D.M. mTOR Signaling in Growth, Metabolism, and Disease. Cell 2017, 168, 960-976. [CrossRef]

80. Nojima, H.; Tokunaga, C.; Eguchi, S.; Oshiro, N.; Hidayat, S.; Yoshino, K.-i.; Hara, K.; Tanaka, N.; Avruch, J.; Yonezawa, K. The Mammalian Target of Rapamycin (mTOR) Partner, Raptor, Binds the mTOR Substrates p70 S6 Kinase and 4E-BP1 through Their TOR Signaling (TOS) Motif. J. Biol. Chem. 2003, 278, 15461-15464. [CrossRef] [PubMed]

81. Dos, D.S.; Ali, S.M.; Kim, D.-H.; Guertin, D.A.; Latek, R.R.; Erdjument-Bromage, H.; Tempst, P.; Sabatini, D.M. Rictor, a Novel Binding Partner of mTOR, Defines a Rapamycin-Insensitive and Raptor-Independent Pathway that Regulates the Cytoskeleton. Curr. Biol. 2004, 14, 1296-1302. [CrossRef]

82. Baas, A.F.; Boudeau, J.; Sapkota, G.P.; Smit, L.; Medema, R.; Morrice, N.A.; Alessi, D.R.; Clevers, H.C. Activation of the tumour suppressor kinase LKB1 by the STE20-like pseudokinase STRAD. EMBO J. 2003, 22, 3062-3072. [CrossRef]

83. Boudeau, J.; Baas, A.F.; Deak, M.; Morrice, N.A.; Kieloch, A.; Schutkowski, M.; Prescott, A.R.; Clevers, H.C.; Alessi, D.R. MO25alpha/beta interact with STRADalpha/beta enhancing their ability to bind, activate and localize LKB1 in the cytoplasm. EMBO J. 2003, 22, 5102-5114. [CrossRef] 
84. Marignani, P.A.; Scott, K.D.; Bagnulo, R.; Cannone, D.; Ferrari, E.; Stella, A.; Guanti, G.; Simone, C.; Resta, N. Novel Splice Isoforms of STRADalpha Differentially Affect LKB1 Activity, Complex Assembly and Subcellular Localization. Cancer Biol. Ther. 2007, 6, 1627-1631. [CrossRef] [PubMed]

85. Hong, S.-P.; Leiper, F.C.; Woods, A.; Carling, D.; Carlson, M. Activation of yeast Snf1 and mammalian AMP-activated protein kinase by upstream kinases. Proc. Natl. Acad. Sci. USA 2003, 100, 8839-8843. [CrossRef] [PubMed]

86. Lizcano, J.M.; Goransson, O.; Toth, R.; Deak, M.; Morrice, N.A.; Boudeau, J.; Hawley, S.A.; Udd, L.; Makela, T.P.; Hardie, D.G.; et al. LKB1 is a master kinase that activates 13 kinases of the AMPK subfamily, including MARK/PAR-1. EMBO J. 2004, 23, 833-843. [CrossRef] [PubMed]

87. Corradetti, M.N.; Inoki, K.; Bardeesy, N.; DePinho, R.A.; Guan, K.-L. Regulation of the TSC pathway by LKB1: Evidence of a molecular link between tuberous sclerosis complex and Peutz-Jeghers syndrome. Genes Dev. 2004, 18, 1533-1538. [CrossRef] [PubMed]

88. Tee, A.R.; Manning, B.D.; Roux, P.P.; Cantley, L.C.; Blenis, J. Tuberous Sclerosis Complex Gene Products, Tuberin and Hamartin, Control mTOR Signaling by Acting as a GTPase-Activating Protein Complex toward Rheb. Curr. Biol. 2003, 13, 1259-1268. [CrossRef]

89. Agarwal, S.; Bell, C.M.; Rothbart, S.B.; Moran, R.G. AMP-activated Protein Kinase (AMPK) Control of mTORC1 Is p53- and TSC2-independent in Pemetrexed-treated Carcinoma Cells. J. Biol. Chem. 2015, 290, 27473-27486. [CrossRef]

90. Alessi, D.R.; James, S.R.; Downes, C.P.; Holmes, A.B.; Gaffney, P.R.J.; Reese, C.B.; Cohen, P. Characterization of a 3phosphoinositide-dependent protein kinase which phosphorylates and activates protein kinase B $\alpha$. Curr. Biol. 1997, 7, 261-269. [CrossRef]

91. Wadhwa, B.; Makhdoomi, U.; Vishwakarma, R.; Malik, F. Protein kinase B: Emerging mechanisms of isoform-specific regulation of cellular signaling in cancer. Anti-Cancer Drugs 2017, 28, 569-580. [CrossRef]

92. Inoki, K.; Li, Y.; Zhu, T.; Wu, J.; Guan, K.-L. TSC2 is phosphorylated and inhibited by Akt and suppresses mTOR signalling. Nat. Cell Biol. 2002, 4, 648-657. [CrossRef]

93. Reynolds, T.H.; Bodine, S.C.; Lawrence, J.C. Control of Ser2448 Phosphorylation in the Mammalian Target of Rapamycin by Insulin and Skeletal Muscle Load. J. Biol. Chem. 2002, 277, 17657-17662. [CrossRef]

94. Taylor, S.S.; Knighton, D.R.; Zheng, J.; Ten Eyck, L.F.; Sowadski, J.M. Structural Framework for the Protein Kinase Family. Annu. Rev. Cell Biol. 1992, 8, 429-462. [CrossRef]

95. Garton, A.J.; Campbell, D.G.; Cohen, P.; Yeaman, S.J. Primary structure of the site on bovine hormone-sensitive lipase phosphorylated by cyclic AMP-dependent protein kinase. FEBS Lett. 1988, 229, 68-72. [CrossRef]

96. Davis, J.S.; Weakland, L.L.; Farese, R.V.; West, L.A. Luteinizing hormone increases inositol trisphosphate and cytosolic free Ca2+ in isolated bovine luteal cells. J. Biol. Chem. 1987, 262, 8515-8521. [CrossRef]

97. Kari, S.; Vasko, V.V.; Priya, S.; Kirschner, L.S. PKA Activates AMPK Through LKB1 Signaling in Follicular Thyroid Cancer. Front. Endocrinol. (Lausanne) 2019, 10, 769. [CrossRef] [PubMed]

98. Jewell, J.L.; Fu, V.; Hong, A.W.; Yu, F.-X.; Meng, D.; Melick, C.H.; Wang, H.; Lam, W.-L.M.; Yuan, H.-X.; Taylor, S.S.; et al. GPCR signaling inhibits mTORC1 via PKA phosphorylation of Raptor. Elife 2019, 8, e43038. [CrossRef] [PubMed]

99. Anderson, K.A.; Ribar, T.J.; Lin, F.; Noeldner, P.K.; Green, M.F.; Muehlbauer, M.J.; Witters, L.A.; Kemp, B.E.; Means, A.R. Hypothalamic CaMKK2 Contributes to the Regulation of Energy Balance. Cell Metab. 2008, 7, 377-388. [CrossRef]

100. Neumann, D. Is TAK1 a Direct Upstream Kinase of AMPK? Int. J. Mol. Sci. 2018, 19, 2412. [CrossRef]

101. Momcilovic, M.; Hong, S.-P.; Carlson, M. Mammalian TAK1 Activates Snf1 Protein Kinase in Yeast and Phosphorylates AMPactivated Protein Kinase in vitro*. J. Biol. Chem. 2006, 281, 25336-25343. [CrossRef]

102. Ovens, A.J.; Scott, J.W.; Langendorf, C.G.; Kemp, B.E.; Oakhill, J.S.; Smiles, W.J. Post-Translational Modifications of the Energy Guardian AMP-Activated Protein Kinase. Int. J. Mol. Sci. 2021, 22, 1229. [CrossRef]

103. Richter, J.D.; Sonenberg, N. Regulation of cap-dependent translation by eIF4E inhibitory proteins. Nature 2005, 433, 477-480. [CrossRef]

104. Gingras, A.C.; Gygi, S.P.; Raught, B.; Polakiewicz, R.D.; Abraham, R.T.; Hoekstra, M.F.; Aebersold, R.; Sonenberg, N. Regulation of 4E-BP1 phosphorylation: A novel two-step mechanism. Genes Dev. 1999, 13, 1422-1437. [CrossRef] [PubMed]

105. Holz, M.K.; Ballif, B.A.; Gygi, S.P.; Blenis, J. mTOR and S6K1 Mediate Assembly of the Translation Preinitiation Complex through Dynamic Protein Interchange and Ordered Phosphorylation Events. Cell 2005, 123, 569-580. [CrossRef]

106. Fingar, D.; Richardson, C.; Tee, A.; Cheatham, L.; Tsou, C.; Blenis, J. mTOR controls cell cycle progression through its cell growth effectors S6K1 and 4E-BP1/eukaryotic translation initiation factor 4E. Mol. Cell Biol. 2004, 24, 200-216. [CrossRef]

107. Averous, J.; Fonseca, B.D.; Proud, C.G. Regulation of cyclin D1 expression by mTORC1 signaling requires eukaryotic initiation factor 4E-binding protein 1. Oncogene 2008, 27, 1106-1113. [CrossRef]

108. Knudsen, E.S.; Kumarasamy, V.; Ruiz, A.; Sivinski, J.; Chung, S.; Grant, A.; Vail, P.; Chauhan, S.S.; Jie, T.; Riall, T.S.; et al. Cell cycle plasticity driven by MTOR signaling: Integral resistance to CDK4/6 inhibition in patient-derived models of pancreatic cancer. Oncogene 2019, 38, 3355-3370. [CrossRef]

109. Harrington, L.S.; Findlay, G.M.; Gray, A.; Tolkacheva, T.; Wigfield, S.; Rebholz, H.; Barnett, J.; Leslie, N.R.; Cheng, S.; Shepherd, P.R.; et al. The TSC1-2 tumor suppressor controls insulin-PI3K signaling via regulation of IRS proteins. J. Cell Biol. 2004, 166, 213-223. [CrossRef] [PubMed] 
110. Yoneyama, Y.; Inamitsu, T.; Chida, K.; Iemura, S.-I.; Natsume, T.; Maeda, T.; Hakuno, F.; Takahashi, S.-I. Serine Phosphorylation by mTORC1 Promotes IRS-1 Degradation through SCF $\beta$-TRCP E3 Ubiquitin Ligase. iScience 2018, 5, 1-18. [CrossRef] [PubMed]

111. Carracedo, A.; Ma, L.; Teruya-Feldstein, J.; Rojo, F.; Salmena, L.; Alimonti, A.; Egia, A.; Sasaki, A.T.; Thomas, G.; Kozma, S.C.; et al. Inhibition of mTORC1 leads to MAPK pathway activation through a PI3K-dependent feedback loop in human cancer. J. Clin. Investig. 2008, 118, 3065-3074. [CrossRef]

112. Düvel, K.; Yecies, J.L.; Menon, S.; Raman, P.; Lipovsky, A.I.; Souza, A.L.; Triantafellow, E.; Ma, Q.; Gorski, R.; Cleaver, S.; et al. Activation of a metabolic gene regulatory network downstream of mTOR complex 1. Mol. Cell 2010, 39, 171-183. [CrossRef]

113. Finlay, D.K.; Rosenzweig, E.; Sinclair, L.V.; Feijoo-Carnero, C.; Hukelmann, J.L.; Rolf, J.; Panteleyev, A.A.; Okkenhaug, K.; Cantrell, D.A. PDK1 regulation of mTOR and hypoxia-inducible factor 1 integrate metabolism and migration of CD8+ T cells. J. Exp. Med. 2012, 209, 2441-2453. [CrossRef]

114. Poulain, L.; Sujobert, P.; Zylbersztejn, F.; Barreau, S.; Stuani, L.; Lambert, M.; Palama, T.L.; Chesnais, V.; Birsen, R.; Vergez, F.; et al. High mTORC1 activity drives glycolysis addiction and sensitivity to G6PD inhibition in acute myeloid leukemia cells. Leukemia 2017, 31, 2326-2335. [CrossRef]

115. Porstmann, T.; Santos, C.R.; Griffiths, B.; Cully, M.; Wu, M.; Leevers, S.; Griffiths, J.R.; Chung, Y.-L.; Schulze, A. SREBP activity is regulated by mTORC1 and contributes to Akt-dependent cell growth. Cell Metab. 2008, 8, 224-236. [CrossRef]

116. Kim, J.E.; Chen, J. regulation of peroxisome proliferator-activated receptor-gamma activity by mammalian target of rapamycin and amino acids in adipogenesis. Diabetes 2004, 53, 2748-2756. [CrossRef]

117. Morita, M.; Gravel, S.-P.; Chénard, V.; Sikström, K.; Zheng, L.; Alain, T.; Gandin, V.; Avizonis, D.; Arguello, M.; Zakaria, C.; et al. mTORC1 Controls Mitochondrial Activity and Biogenesis through 4E-BP-Dependent Translational Regulation. Cell Metab. 2013, 18, 698-711. [CrossRef]

118. Cunningham, J.T.; Rodgers, J.T.; Arlow, D.H.; Vazquez, F.; Mootha, V.K.; Puigserver, P. mTOR controls mitochondrial oxidative function through a YY1-PGC-1 $\alpha$ transcriptional complex. Nature 2007, 450, 736-740. [CrossRef] [PubMed]

119. Bentzinger, C.F.; Romanino, K.; Cloëtta, D.; Lin, S.; Mascarenhas, J.B.; Oliveri, F.; Xia, J.; Casanova, E.; Costa, C.F.; Brink, M.; et al. Skeletal Muscle-Specific Ablation of raptor, but Not of rictor, Causes Metabolic Changes and Results in Muscle Dystrophy. Cell Metab. 2008, 8, 411-424. [CrossRef]

120. Ganley, I.G.; Lam, D.H.; Wang, J.; Ding, X.; Chen, S.; Jiang, X. ULK1·ATG13·FIP200 Complex Mediates mTOR Signaling and Is Essential for Autophagy. J. Biol. Chem. 2009, 284, 12297-12305. [CrossRef] [PubMed]

121. Kim, J.; Kundu, M.; Viollet, B.; Guan, K.-L. AMPK and mTOR regulate autophagy through direct phosphorylation of Ulk1. Nat. Cell Biol. 2011, 13, 132-141. [CrossRef] [PubMed]

122. Julien, L.-A.; Carriere, A.; Moreau, J.; Roux, P.P. mTORC1-activated S6K1 phosphorylates Rictor on threonine 1135 and regulates mTORC2 signaling. Mol. Cell Biol. 2010, 30, 908-921. [CrossRef]

123. Dibble, C.C.; Asara, J.M.; Manning, B.D. Characterization of Rictor phosphorylation sites reveals direct regulation of mTOR complex 2 by S6K1. Mol. Cell Biol. 2009, 29, 5657-5670. [CrossRef]

124. Liu, P.; Gan, W.; Inuzuka, H.; Lazorchak, A.S.; Gao, D.; Arojo, O.; Liu, D.; Wan, L.; Zhai, B.; Yu, Y.; et al. Sin1 phosphorylation impairs mTORC2 complex integrity and inhibits downstream Akt signalling to suppress tumorigenesis. Nat. Cell Biol. 2013, 15, 1340-1350. [CrossRef]

125. Gao, M.; Kong, Q.; Hua, H.; Yin, Y.; Wang, J.; Luo, T.; Jiang, Y. AMPK-mediated up-regulation of mTORC2 and MCL-1 compromises the anti-cancer effects of aspirin. Oncotarget 2016, 7, 16349-16361. [CrossRef] [PubMed]

126. Jacinto, E.; Loewith, R.; Schmidt, A.; Lin, S.; Rüegg, M.A.; Hall, A.; Hall, M.N. Mammalian TOR complex 2 controls the actin cytoskeleton and is rapamycin insensitive. Nat. Cell Biol. 2004, 6, 1122-1128. [CrossRef] [PubMed]

127. Sarbassov, D.D.; Guertin, D.A.; Ali, S.M.; Sabatini, D.M. Phosphorylation and Regulation of Akt/PKB by the Rictor-mTOR Complex. Science 2005, 307, 1098. [CrossRef] [PubMed]

128. Jacinto, E.; Facchinetti, V.; Liu, D.; Soto, N.; Wei, S.; Jung, S.Y.; Huang, Q.; Qin, J.; Su, B. SIN1/MIP1 Maintains rictor-mTOR Complex Integrity and Regulates Akt Phosphorylation and Substrate Specificity. Cell 2006, 127, 125-137. [CrossRef] [PubMed]

129. Shiota, C.; Woo, J.-T.; Lindner, J.; Shelton, K.D.; Magnuson, M.A. Multiallelic Disruption of the rictor Gene in Mice Reveals that mTOR Complex 2 Is Essential for Fetal Growth and Viability. Dev. Cell 2006, 11, 583-589. [CrossRef]

130. Yang, Q.; Inoki, K.; Ikenoue, T.; Guan, K.-L. Identification of Sin1 as an essential TORC2 component required for complex formation and kinase activity. Genes Dev. 2006, 20, 2820-2832. [CrossRef]

131. Hagiwara, A.; Cornu, M.; Cybulski, N.; Polak, P.; Betz, C.; Trapani, F.; Terracciano, L.; Heim, M.H.; Rüegg, M.A.; Hall, M.N. Hepatic mTORC2 Activates Glycolysis and Lipogenesis through Akt, Glucokinase, and SREBP1c. Cell Metab. 2012, 15, 725-738. [CrossRef]

132. Masui, K.; Tanaka, K.; Akhavan, D.; Babic, I.; Gini, B.; Matsutani, T.; Iwanami, A.; Liu, F.; Villa, G.R.; Gu, Y.; et al. mTOR complex 2 controls glycolytic metabolism in glioblastoma through FoxO acetylation and up-regulation of c-Myc. Cell Metab. 2013, 18, 726-739. [CrossRef]

133. Xu, Z.; Xu, M.; Liu, P.; Zhang, S.; Shang, R.; Qiao, Y.; Che, L.; Ribback, S.; Cigliano, A.; Evert, K.; et al. The mTORC2-Akt1 Cascade Is Crucial for c-Myc to Promote Hepatocarcinogenesis in Mice and Humans. Hepatology 2019, 70, 1600-1613. [CrossRef]

134. Powell, J.D.; Pollizzi, K.N.; Heikamp, E.B.; Horton, M.R. Regulation of immune responses by mTOR. Annu. Rev. Immunol. 2012, 30, 39-68. [CrossRef] [PubMed] 
135. Conciatori, F.; Bazzichetto, C.; Falcone, I.; Pilotto, S.; Bria, E.; Cognetti, F.; Milella, M.; Ciuffreda, L. Role of mTOR Signaling in Tumor Microenvironment: An Overview. Int. J. Mol. Sci. 2018, 19, 2453. [CrossRef]

136. Brown, E.J.; Albers, M.W.; Bum Shin, T.; ichikawa, K.; Keith, C.T.; Lane, W.S.; Schreiber, S.L. A mammalian protein targeted by G1-arresting rapamycin-receptor complex. Nature 1994, 369, 756-758. [CrossRef]

137. Choi, J.; Chen, J.; Schreiber, S.L.; Clardy, J. Structure of the FKBP12-Rapamycin Complex Interacting with Binding Domain of Human FRAP. Science 1996, 273, 239. [CrossRef] [PubMed]

138. Sarbassov, D.D.; Ali, S.M.; Sengupta, S.; Sheen, J.-H.; Hsu, P.P.; Bagley, A.F.; Markhard, A.L.; Sabatini, D.M. Prolonged Rapamycin Treatment Inhibits mTORC2 Assembly and Akt/PKB. Mol. Cell 2006, 22, 159-168. [CrossRef] [PubMed]

139. Zoncu, R.; Efeyan, A.; Sabatini, D.M. mTOR: From growth signal integration to cancer, diabetes and ageing. Nat. Rev. Mol. Cell Biol. 2011, 12, 21-35. [CrossRef]

140. Jacobsen, W.; Serkova, N.; Hausen, B.; Morris, R.E.; Benet, L.Z.; Christians, U. Comparison of the in vitro metabolism of the macrolide immunosuppressants sirolimus and RAD. Transplant. Proc. 2001, 33, 514-515. [CrossRef]

141. Augustine, J.J.; Hricik, D.E. Experience with everolimus. Transplant. Proc. 2004, 36, S500-S503. [CrossRef]

142. Dudkin, L.; Dilling, M.B.; Cheshire, P.J.; Harwood, F.C.; Hollingshead, M.; Arbuck, S.G.; Travis, R.; Sausville, E.A.; Houghton, P.J Biochemical Correlates of mTOR Inhibition by the Rapamycin Ester CCI-779 and Tumor Growth Inhibition. Clin. Cancer Res. 2001, 7, 1758. [PubMed]

143. Crowe, A.; Bruelisauer, A.; Duerr, L.; Guntz, P.; Lemaire, M. Absorption and Intestinal Metabolism of SDZ-RAD and Rapamycin in Rats. Drug Metab. Dispos. 1999, 27, 627. [PubMed]

144. Corradetti, M.N.; Guan, K.L. Upstream of the mammalian target of rapamycin: Do all roads pass through mTOR? Oncogene 2006, 25, 6347-6360. [CrossRef] [PubMed]

145. Hudson, C.C.; Liu, M.; Chiang, G.G.; Otterness, D.M.; Loomis, D.C.; Kaper, F.; Giaccia, A.J.; Abraham, R.T. Regulation of hypoxia-inducible factor 1alpha expression and function by the mammalian target of rapamycin. Mol. Cell Biol. 2002, 22, 7004-7014. [CrossRef] [PubMed]

146. Mita, M.M.; Mita, A.C.; Chu, Q.S.; Rowinsky, E.K.; Fetterly, G.J.; Goldston, M.; Patnaik, A.; Mathews, L.; Ricart, A.D.; Mays, T.; et al. Phase I Trial of the Novel Mammalian Target of Rapamycin Inhibitor Deforolimus (AP23573; MK-8669) Administered Intravenously Daily for 5 Days Every 2 Weeks to Patients with Advanced Malignancies. J. Clin. Oncol. 2008, 26, 361-367. [CrossRef] [PubMed]

147. O'Reilly, K.E.; Rojo, F.; She, Q.-B.; Solit, D.; Mills, G.B.; Smith, D.; Lane, H.; Hofmann, F.; Hicklin, D.J.; Ludwig, D.L.; et al. mTOR inhibition induces upstream receptor tyrosine kinase signaling and activates Akt. Cancer Res. 2006, 66, 1500-1508. [CrossRef]

148. Li, J.; Kim, S.G.; Blenis, J. Rapamycin: One drug, many effects. Cell Metab. 2014, 19, 373-379. [CrossRef]

149. Thoreen, C.C.; Kang, S.A.; Chang, J.W.; Liu, Q.; Zhang, J.; Gao, Y.; Reichling, L.J.; Sim, T.; Sabatini, D.M.; Gray, N.S. An ATPcompetitive mammalian target of rapamycin inhibitor reveals rapamycin-resistant functions of mTORC1. J. Biol. Chem. 2009, 284, 8023-8032. [CrossRef]

150. Chresta, C.M.; Davies, B.R.; Hickson, I.; Harding, T.; Cosulich, S.; Critchlow, S.E.; Vincent, J.P.; Ellston, R.; Jones, D.; Sini, P.; et al. AZD8055 Is a Potent, Selective, and Orally Bioavailable ATP-Competitive Mammalian Target of Rapamycin Kinase Inhibitor with In vitro and In vivo Antitumor Activity. Cancer Res. 2010, 70, 288. [CrossRef]

151. Andrade-Vieira, R.; Goguen, D.; Bentley, H.A.; Bowen, C.V.; Marignani, P.A. Pre-clinical study of drug combinations that reduce breast cancer burden due to aberrant mTOR and metabolism promoted by LKB1 loss. Oncotarget 2014, 5, 12738-12752. [CrossRef] [PubMed]

152. Guichard, S.M.; Curwen, J.; Bihani, T.; Cruz, C.M.; Yates, J.W.T.; Grondine, M.; Howard, Z.; Davies, B.R.; Bigley, G.; Klinowska, T.; et al. AZD2014, an Inhibitor of mTORC1 and mTORC2, Is Highly Effective in ER ${ }^{+}$Breast Cancer When Administered Using Intermittent or Continuous Schedules. Mol. Cancer Ther. 2015, 14, 2508. [CrossRef]

153. Engelman, J.A.; Chen, L.; Tan, X.; Crosby, K.; Guimaraes, A.R.; Upadhyay, R.; Maira, M.; McNamara, K.; Perera, S.A.; Song, Y.; et al. Effective use of PI3K and MEK inhibitors to treat mutant Kras G12D and PIK3CA H1047R murine lung cancers. Nat. Med. 2008, 14, 1351-1356. [CrossRef]

154. Liu, Q.; Thoreen, C.; Wang, J.; Sabatini, D.; Gray, N.S. mTOR Mediated Anti-Cancer Drug Discovery. Drug Discov. Today Ther. Strateg. 2009, 6, 47-55. [CrossRef] [PubMed]

155. Schmid, P.; Zaiss, M.; Harper-Wynne, C.; Ferreira, M.; Dubey, S.; Chan, S.; Makris, A.; Nemsadze, G.; Brunt, A.M.; Kuemmel, S.; et al. Fulvestrant Plus Vistusertib vs Fulvestrant Plus Everolimus vs Fulvestrant Alone for Women with Hormone ReceptorPositive Metastatic Breast Cancer: The MANTA Phase 2 Randomized Clinical Trial. JAMA Oncol. 2019, 5, 1556-1564. [CrossRef]

156. Bendell, J.C.; Kelley, R.K.; Shih, K.C.; Grabowsky, J.A.; Bergsland, E.; Jones, S.; Martin, T.; Infante, J.R.; Mischel, P.S.; Matsutani, T.; et al. A phase I dose-escalation study to assess safety, tolerability, pharmacokinetics, and preliminary efficacy of the dual mTORC1/mTORC2 kinase inhibitor CC-223 in patients with advanced solid tumors or multiple myeloma. Cancer 2015, 121, 3481-3490. [CrossRef] [PubMed]

157. Wolin, E.; Mita, A.; Mahipal, A.; Meyer, T.; Bendell, J.; Nemunaitis, J.; Munster, P.N.; Paz-Ares, L.; Filvaroff, E.H.; Li, S.; et al. A phase 2 study of an oral mTORC1/mTORC2 kinase inhibitor (CC-223) for non-pancreatic neuroendocrine tumors with or without carcinoid symptoms. PLoS ONE 2019, 14, e0221994. [CrossRef] [PubMed] 
158. Maira, S.-M.; Stauffer, F.; Brueggen, J.; Furet, P.; Schnell, C.; Fritsch, C.; Brachmann, S.; Chène, P.; De Pover, A.; Schoemaker, K.; et al. Identification and characterization of NVP-BEZ235, a new orally available dual phosphatidylinositol 3-kinase/mammalian target of rapamycin inhibitor with potent in vivo antitumor activity. Mol. Cancer Ther. 2008, 7, 1851-1863. [CrossRef]

159. Massard, C.; Chi, K.N.; Castellano, D.; de Bono, J.; Gravis, G.; Dirix, L.; Machiels, J.-P.; Mita, A.; Mellado, B.; Turri, S.; et al. Phase $\mathrm{Ib}$ dose-finding study of abiraterone acetate plus buparlisib (BKM120) or dactolisib (BEZ235) in patients with castration-resistant prostate cancer. Eur. J. Cancer 2017, 76, 36-44. [CrossRef]

160. Carlo, M.I.; Molina, A.M.; Lakhman, Y.; Patil, S.; Woo, K.; DeLuca, J.; Lee, C.-H.; Hsieh, J.J.; Feldman, D.R.; Motzer, R.J.; et al. A Phase Ib Study of BEZ235, a Dual Inhibitor of Phosphatidylinositol 3-Kinase (PI3K) and Mammalian Target of Rapamycin (mTOR), in Patients with Advanced Renal Cell Carcinoma. Oncologist 2016, 21, 787-788. [CrossRef]

161. Wise-Draper, T.M.; Moorthy, G.; Salkeni, M.A.; Karim, N.A.; Thomas, H.E.; Mercer, C.A.; Beg, M.S.; O'Gara, S.; Olowokure, O.; Fathallah, H.; et al. A Phase Ib Study of the Dual PI3K/mTOR Inhibitor Dactolisib (BEZ235) Combined with Everolimus in Patients with Advanced Solid Malignancies. Target. Oncol. 2017, 12, 323-332. [CrossRef]

162. Raynaud, F.I.; Eccles, S.; Clarke, P.A.; Hayes, A.; Nutley, B.; Alix, S.; Henley, A.; Di-Stefano, F.; Ahmad, Z.; Guillard, S.; et al. Pharmacologic Characterization of a Potent Inhibitor of Class I Phosphatidylinositide 3-Kinases. Cancer Res. 2007, 67, 5840. [CrossRef]

163. Gedaly, R.; Angulo, P.; Hundley, J.; Daily, M.F.; Chen, C.; Koch, A.; Evers, B.M. PI-103 and sorafenib inhibit hepatocellular carcinoma cell proliferation by blocking Ras/Raf/MAPK and PI3K/Akt/mTOR pathways. Anticancer Res. 2010, 30, 4951-4958.

164. Andre, F.; Campone, M.; O’Regan, R.; Manlius, C.; Massacesi, C.; Tarek, S.; Mukhopadhyay, P.; Soria, J.-C.; Naughton, M.; Hurvitz, S.A. Phase I Study of Everolimus Plus Weekly Paclitaxel and Trastuzumab in Patients with Metastatic Breast Cancer Pretreated with Trastuzumab. J. Clin. Oncol. 2010, 28, 5110-5115. [CrossRef]

165. Hurvitz, S.A.; Andre, F.; Jiang, Z.; Shao, Z.; Mano, M.S.; Neciosup, S.P.; Tseng, L.-M.; Zhang, Q.; Shen, K.; Liu, D.; et al. Combination of everolimus with trastuzumab plus paclitaxel as first-line treatment for patients with HER2-positive advanced breast cancer (BOLERO-1): A phase 3, randomised, double-blind, multicentre trial. Lancet Oncol. 2015, 16, 816-829. [CrossRef]

166. Toi, M.; Shao, Z.; Hurvitz, S.; Tseng, L.-M.; Zhang, Q.; Shen, K.; Liu, D.; Feng, J.; Xu, B.; Wang, X.; et al. Efficacy and safety of everolimus in combination with trastuzumab and paclitaxel in Asian patients with HER2+ advanced breast cancer in BOLERO-1. Breast Cancer Res. 2017, 19, 47. [CrossRef]

167. André, F.; O’Regan, R.; Ozguroglu, M.; Toi, M.; Xu, B.; Jerusalem, G.; Masuda, N.; Wilks, S.; Arena, F.; Isaacs, C.; et al. Everolimus for women with trastuzumab-resistant, HER2-positive, advanced breast cancer (BOLERO-3): A randomised, double-blind, placebo-controlled phase 3 trial. Lancet Oncol. 2014, 15, 580-591. [CrossRef]

168. Seiler, M.; Ray-Coquard, I.; Melichar, B.; Yardley, D.A.; Wang, R.X.; Dodion, P.F.; Lee, M.A. Oral Ridaforolimus Plus Trastuzumab for Patients with HER2+ Trastuzumab-Refractory Metastatic Breast Cancer. Clin. Breast Cancer 2015, 15, 60-65. [CrossRef] [PubMed]

169. Van Swearingen, A.E.D.; Siegel, M.B.; Deal, A.M.; Sambade, M.J.; Hoyle, A.; Hayes, D.N.; Jo, H.; Little, P.; Dees, E.C.; Muss, H.; et al. LCCC 1025: A phase II study of everolimus, trastuzumab, and vinorelbine to treat progressive HER2-positive breast cancer brain metastases. Breast Cancer Res. Treat. 2018, 171, 637-648. [CrossRef] [PubMed]

170. Gulati, N.; Karsy, M.; Albert, L.; Murali, R.; Jhanwar-Uniyal, M. Involvement of mTORC1 and mTORC2 in regulation of glioblastoma multiforme growth and motility. Int. J. Oncol. 2009, 35, 731-740. [CrossRef] [PubMed]

171. Cloughesy, T.F.; Yoshimoto, K.; Nghiemphu, P.; Brown, K.; Dang, J.; Zhu, S.; Hsueh, T.; Chen, Y.; Wang, W.; Youngkin, D.; et al. Antitumor Activity of Rapamycin in a Phase I Trial for Patients with Recurrent PTEN-Deficient Glioblastoma. PLoS Med. 2008, 5, e8. [CrossRef] [PubMed]

172. O’Brien, N.A.; McDonald, K.; Tong, L.; von Euw, E.; Kalous, O.; Conklin, D.; Hurvitz, S.A.; di Tomaso, E.; Schnell, C.; Linnartz, R.; et al. Targeting PI3K/mTOR Overcomes Resistance to HER2-Targeted Therapy Independent of Feedback Activation of Akt. Clin. Cancer Res. 2014, 20, 3507-3520. [CrossRef] [PubMed]

173. Rodon, J.; Pérez-Fidalgo, A.; Krop, I.E.; Burris, H.; Guerrero-Zotano, A.; Britten, C.D.; Becerra, C.; Schellens, J.; Richards, D.A.; Schuler, M.; et al. Phase $1 / 1 \mathrm{~b}$ dose escalation and expansion study of BEZ235, a dual PI3K/mTOR inhibitor, in patients with advanced solid tumors including patients with advanced breast cancer. Cancer Chemother. Pharmacol. 2018, 82, 285-298. [CrossRef]

174. Hua, H.; Kong, Q.; Zhang, H.; Wang, J.; Luo, T.; Jiang, Y. Targeting mTOR for cancer therapy. J. Hematol. Oncol. 2019, 12, 71. [CrossRef]

175. Tian, T.; Li, X.; Zhang, J. mTOR Signaling in Cancer and mTOR Inhibitors in Solid Tumor Targeting Therapy. Int. J. Mol. Sci. 2019, 20, 755. [CrossRef]

176. Jerusalem, G.; Fasolo, A.; Dieras, V.; Cardoso, F.; Bergh, J.; Vittori, L.; Zhang, Y.; Massacesi, C.; Sahmoud, T.; Gianni, L. Phase I trial of oral mTOR inhibitor everolimus in combination with trastuzumab and vinorelbine in pre-treated patients with HER2-overexpressing metastatic breast cancer. Breast Cancer Res. Treat. 2011, 125, 447-455. [CrossRef]

177. Muller, W.J.; Sinn, E.; Pattengale, P.K.; Wallace, R.; Leder, P. Single-step induction of mammary adenocarcinoma in transgenic mice bearing the activated c-neu oncogene. Cell 1988, 54, 105-115. [CrossRef]

178. Ursini-Siegel, J.; Schade, B.; Cardiff, R.D.; Muller, W.J. Insights from transgenic mouse models of ERBB2-induced breast cancer. Nat. Rev. Cancer 2007, 7, 389-397. [CrossRef]

179. Ursini-Siegel, J.; Hardy, W.R.; Zuo, D.M.; Lam, S.H.; Sanguin-Gendreau, V.; Cardiff, R.D.; Pawson, T.; Muller, W.J. ShcA signalling is essential for tumour progression in mouse models of human breast cancer. EMBO J. 2008, 27, 910-920. [CrossRef] 
180. Chen, I.C.; Chang, Y.-C.; Lu, Y.-S.; Chung, K.-P.; Huang, C.-S.; Lu, T.-P.; Kuo, W.-H.; Wang, M.-Y.; Kuo, K.-T.; Wu, P.-F.; et al. Clinical Relevance of Liver Kinase B1(LKB1) Protein and Gene Expression in Breast Cancer. Sci. Rep. 2016, 6, 21374. [CrossRef] [PubMed]

181. Mendoza, M.C.; Er, E.E.; Blenis, J. The Ras-ERK and PI3K-mTOR pathways: Cross-talk and compensation. Trends Biochem. Sci. 2011, 36, 320-328. [CrossRef] [PubMed]

182. Entner, N.; Doudoroff, M. Glucose and Gluconic Acid Oxidation of Pseudomonas Saccharophila. J. Biol. Chem. 1952, 196, 853-862. [CrossRef]

183. Pelicano, H.; Martin, D.S.; Xu, R.H.; Huang, P. Glycolysis inhibition for anticancer treatment. Oncogene 2006, $25,4633-4646$. [CrossRef] [PubMed]

184. Spinelli, J.B.; Haigis, M.C. The multifaceted contributions of mitochondria to cellular metabolism. Nat. Cell Biol. 2018, 20, 745-754. [CrossRef] [PubMed]

185. Rogatzki, M.J.; Ferguson, B.S.; Goodwin, M.L.; Gladden, L.B. Lactate is always the end product of glycolysis. Front. Neurosci. 2015, 9, 22. [CrossRef]

186. Warburg, O.; Wind, F.; Negelein, E. The Metabolism of Tumors in the Body. J. Gen. Physiol. 1927, 8, 519-530. [CrossRef]

187. Lamb, R.; Bonuccelli, G.; Ozsvári, B.; Peiris-Pagès, M.; Fiorillo, M.; Smith, D.L.; Bevilacqua, G.; Mazzanti, C.M.; McDonnell, L.A.; Naccarato, A.G.; et al. Mitochondrial mass, a new metabolic biomarker for stem-like cancer cells: Understanding WNT/FGFdriven anabolic signaling. Oncotarget 2015, 6, 30453-30471. [CrossRef] [PubMed]

188. Davidson, S.M.; Papagiannakopoulos, T.; Olenchock, B.A.; Heyman, J.E.; Keibler, M.A.; Luengo, A.; Bauer, M.R.; Jha, A.K.; O'Brien, J.P.; Pierce, K.A.; et al. Environment Impacts the Metabolic Dependencies of Ras-Driven Non-Small Cell Lung Cancer. Cell Metab. 2016, 23, 517-528. [CrossRef] [PubMed]

189. Pastò, A.; Bellio, C.; Pilotto, G.; Ciminale, V.; Silic-Benussi, M.; Guzzo, G.; Rasola, A.; Frasson, C.; Nardo, G.; Zulato, E.; et al. Cancer stem cells from epithelial ovarian cancer patients privilege oxidative phosphorylation, and resist glucose deprivation. Oncotarget 2014, 5, 4305-4319. [CrossRef] [PubMed]

190. Birsoy, K.; Wang, T.; Chen, W.W.; Freinkman, E.; Abu-Remaileh, M.; Sabatini, D.M. An Essential Role of the Mitochondrial Electron Transport Chain in Cell Proliferation Is to Enable Aspartate Synthesis. Cell 2015, 162, 540-551. [CrossRef]

191. Sullivan, L.B.; Gui, D.Y.; Hosios, A.M.; Bush, L.N.; Freinkman, E.; Vander Heiden, M.G. Supporting Aspartate Biosynthesis Is an Essential Function of Respiration in Proliferating Cells. Cell 2015, 162, 552-563. [CrossRef]

192. King, M.P.; Attardi, G. Human cells lacking mtDNA: Repopulation with exogenous mitochondria by complementation. Science 1989, 246, 500. [CrossRef] [PubMed]

193. Morais, R.; Zinkewich-Péotti, K.; Parent, M.; Wang, H.; Babai, F.; Zollinger, M. Tumor-forming Ability in Athymic Nude Mice of Human Cell Lines Devoid of Mitochondrial DNA. Cancer Res. 1994, 54, 3889. [PubMed]

194. Cavalli, L.R.; Varella-Garcia, M.; Liang, B.C. Diminished tumorigenic phenotype after depletion of mitochondrial DNA. Cell Growth Differ. 1997, 8, 1189-1198.

195. Zhao, Y.; Liu, H.; Liu, Z.; Ding, Y.; Ledoux, S.P.; Wilson, G.L.; Voellmy, R.; Lin, Y.; Lin, W.; Nahta, R.; et al. Overcoming trastuzumab resistance in breast cancer by targeting dysregulated glucose metabolism. Cancer Res. 2011, 71, 4585-4597. [CrossRef]

196. Hudson, C.D.; Hagemann, T.; Mather, S.J.; Avril, N. Resistance to the tyrosine kinase inhibitor axitinib is associated with increased glucose metabolism in pancreatic adenocarcinoma. Cell Death Dis. 2014, 5, e1160. [CrossRef] [PubMed]

197. Herranz, D.; Ambesi-Impiombato, A.; Sudderth, J.; Sánchez-Martín, M.; Belver, L.; Tosello, V.; Xu, L.; Wendorff, A.A.; Castillo, M.; Haydu, J.E.; et al. Metabolic reprogramming induces resistance to anti-NOTCH1 therapies in T cell acute lymphoblastic leukemia. Nat. Med. 2015, 21, 1182-1189. [CrossRef]

198. Morandi, A.; Indraccolo, S. Linking metabolic reprogramming to therapy resistance in cancer. Biochim. Biophys. Acta (BBA) Rev. Cancer 2017, 1868, 1-6. [CrossRef]

199. Gandhi, N.; Das, G.M. Metabolic Reprogramming in Breast Cancer and Its Therapeutic Implications. Cells 2019, 8, 89. [CrossRef]

200. Zhao, Y.H.; Zhou, M.; Liu, H.; Ding, Y.; Khong, H.T.; Yu, D.; Fodstad, O.; Tan, M. Up-regulation of lactate dehydrogenase A by ErbB2 through heat shock factor 1 promotes breast cancer cell glycolysis and growth. Oncogene 2009, 28, 3689-3701. [CrossRef]

201. Cappelletti, V.; Iorio, E.; Miodini, P.; Silvestri, M.; Dugo, M.; Daidone, M.G. Metabolic Footprints and Molecular Subtypes in Breast Cancer. Dis. Markers 2017, 2017, 7687851. [CrossRef]

202. Zhang, P.; Yang, Y.; Qian, K.; Li, L.; Zhang, C.; Fu, X.; Zhang, X.; Chen, H.; Liu, Q.; Cao, S.; et al. A novel tumor suppressor ZBTB1 regulates tamoxifen resistance and aerobic glycolysis through suppressing HER2 expression in breast cancer. J. Biol. Chem. 2020. [CrossRef]

203. Gale, M.; Li, Y.; Cao, J.; Liu, Z.Z.; Holmbeck, M.A.; Zhang, M.; Lang, S.M.; Wu, L.; Do Carmo, M.; Gupta, S.; et al. Acquired Resistance to HER2-Targeted Therapies Creates Vulnerability to ATP Synthase Inhibition. Cancer Res. 2020, 80, 524-535. [CrossRef]

204. Lenz, G.; Hamilton, A.; Geng, S.; Hong, T.; Kalkum, M.; Momand, J.; Kane, S.E.; Huss, J.M. t-Darpp Activates IGF-1R Signaling to Regulate Glucose Metabolism in Trastuzumab-Resistant Breast Cancer Cells. Clin. Cancer Res. 2018, 24, 1216-1226. [CrossRef]

205. Elstrom, R.L.; Bauer, D.E.; Buzzai, M.; Karnauskas, R.; Harris, M.H.; Plas, D.R.; Zhuang, H.; Cinalli, R.M.; Alavi, A.; Rudin, C.M.; et al. Akt Stimulates Aerobic Glycolysis in Cancer Cells. Cancer Res. 2004, 64, 3892. [CrossRef] 
206. Rathmell, J.C.; Fox, C.J.; Plas, D.R.; Hammerman, P.S.; Cinalli, R.M.; Thompson, C.B. Akt-directed glucose metabolism can prevent Bax conformation change and promote growth factor-independent survival. Mol. Cell Biol. 2003, 23, 7315-7328. [CrossRef]

207. Dutchak, P.A.; Estill-Terpack, S.J.; Plec, A.A.; Zhao, X.; Yang, C.; Chen, J.; Ko, B.; Deberardinis, R.J.; Yu, Y.; Tu, B.P. Loss of a Negative Regulator of mTORC1 Induces Aerobic Glycolysis and Altered Fiber Composition in Skeletal Muscle. Cell Rep. 2018, 23, 1907-1914. [CrossRef] [PubMed]

208. Koboldt, D.C.; Fulton, R.S.; McLellan, M.D.; Schmidt, H.; Kalicki-Veizer, J.; McMichael, J.F.; Fulton, L.L.; Dooling, D.J.; Ding, L.; Mardis, E.R.; et al. Comprehensive molecular portraits of human breast tumours. Nature 2012, 490, 61-70. [CrossRef]

209. Bost, F.; Decoux-Poullot, A.G.; Tanti, J.F.; Clavel, S. Energy disruptors: Rising stars in anticancer therapy? Oncogenesis 2016, 5, e188. [CrossRef]

210. Maher, J.C.; Krishan, A.; Lampidis, T.J. Greater cell cycle inhibition and cytotoxicity induced by 2-deoxy-d-glucose in tumor cells treated under hypoxic vs aerobic conditions. Cancer Chemother. Pharmacol. 2004, 53, 116-122. [CrossRef] [PubMed]

211. Zhong, D.; Liu, X.; Schafer-Hales, K.; Marcus, A.I.; Khuri, F.R.; Sun, S.-Y.; Zhou, W. 2-Deoxyglucose induces Akt phosphorylation via a mechanism independent of LKB1/AMP-activated protein kinase signaling activation or glycolysis inhibition. Mol. Cancer Ther. 2008, 7, 809-817. [CrossRef]

212. Tsurutani, J.; Fukuoka, J.; Tsurutani, H.; Shih, J.H.; Hewitt, S.M.; Travis, W.D.; Jen, J.; Dennis, P.A. Evaluation of Two Phosphorylation Sites Improves the Prognostic Significance of Akt Activation in Non-Small-Cell Lung Cancer Tumors. J. Clin. Oncol. 2006, 24, 306-314. [CrossRef]

213. Xi, H.; Kurtoglu, M.; Liu, H.; Wangpaichitr, M.; You, M.; Liu, X.; Savaraj, N.; Lampidis, T.J. 2-Deoxy-D-glucose activates autophagy via endoplasmic reticulum stress rather than ATP depletion. Cancer Chemother. Pharmacol. 2011, 67, 899-910. [CrossRef]

214. O’Neal, J.; Clem, A.; Reynolds, L.; Dougherty, S.; Imbert-Fernandez, Y.; Telang, S.; Chesney, J.; Clem, B.F. Inhibition of 6phosphofructo-2-kinase (PFKFB3) suppresses glucose metabolism and the growth of HER2+ breast cancer. Breast Cancer Res. Treat. 2016, 160, 29-40. [CrossRef]

215. DeSalvo, J.; Kuznetsov, J.N.; Du, J.; Leclerc, G.M.; Leclerc, G.J.; Lampidis, T.J.; Barredo, J.C. Inhibition of Akt Potentiates 2-DGInduced Apoptosis via Down-regulation of UPR in Acute Lymphoblastic Leukemia. Mol. Cancer Res. 2012, 10, 969. [CrossRef] [PubMed]

216. Hurley, R.; Anderson, K.; Franzone, J.; Kemp, B.; Means, A.; Witters, L. The Ca2+/calmodulin-dependent protein kinase kinases are AMP-activated protein kinase kinases. J. Biol. Chem. 2005, 280, 29060-29066. [CrossRef]

217. Konagaya, Y.; Terai, K.; Hirao, Y.; Takakura, K.; Imajo, M.; Kamioka, Y.; Sasaoka, N.; Kakizuka, A.; Sumiyama, K.; Asano, T.; et al. A Highly Sensitive FRET Biosensor for AMPK Exhibits Heterogeneous AMPK Responses among Cells and Organs. Cell Rep. 2017, 21, 2628-2638. [CrossRef] [PubMed]

218. Ishikawa, Y.; Tokumitsu, H.; Inuzuka, H.; Murata-Hori, M.; Hosoya, H.; Kobayashi, R. Identification and characterization of novel components of a Ca2+/calmodulin-dependent protein kinase cascade in HeLa cells. FEBS Lett. 2003, 550, 57-63. [CrossRef]

219. Raez, L.E.; Papadopoulos, K.; Ricart, A.D.; Chiorean, E.G.; DiPaola, R.S.; Stein, M.N.; Rocha Lima, C.M.; Schlesselman, J.J.; Tolba, K.; Langmuir, V.K.; et al. A phase I dose-escalation trial of 2-deoxy-d-glucose alone or combined with docetaxel in patients with advanced solid tumors. Cancer Chemother. Pharmacol. 2013, 71, 523-530. [CrossRef]

220. Pajak, B.; Siwiak, E.; Sołtyka, M.; Priebe, A.; Zieliński, R.; Fokt, I.; Ziemniak, M.; Jaśkiewicz, A.; Borowski, R.; Domoradzki, T.; et al. 2-Deoxy-d-Glucose and Its Analogs: From Diagnostic to Therapeutic Agents. Int. J. Mol. Sci. 2019, 21, 234. [CrossRef]

221. Vijayaraghavan, R.; Kumar, D.; Dube, S.N.; Singh, R.; Pandey, K.S.; Bag, B.C.; Kaushik, M.P.; Sekhar, K.; Dwarakanath, B.S.; Ravindranath, T. Acute toxicity and cardio-respiratory effects of 2-deoxy-D-glucose: A promising radio sensitiser. Biomed. Environ. Sci. 2006, 19, 96-103.

222. Terse, P.S.; Joshi, P.S.; Bordelon, N.R.; Brys, A.M.; Patton, K.M.; Arndt, T.P.; Sutula, T.P. 2-Deoxy-d-Glucose (2-DG)-Induced Cardiac Toxicity in Rat: NT-proBNP and BNP as Potential Early Cardiac Safety Biomarkers. Int. J. Toxicol. 2016, 35, $284-293$. [CrossRef]

223. Maschek, G.; Savaraj, N.; Priebe, W.; Braunschweiger, P.; Hamilton, K.; Tidmarsh, G.F.; De Young, L.R.; Lampidis, T.J. 2-Deoxy-Dglucose Increases the Efficacy of Adriamycin and Paclitaxel in Human Osteosarcoma and Non-Small Cell Lung Cancers In Vivo. Cancer Res. 2004, 64, 31-34. [CrossRef]

224. Sun, L.; Liu, X.; Fu, H.; Zhou, W.; Zhong, D. 2-Deoxyglucose Suppresses ERK Phosphorylation in LKB1 and Ras Wild-Type Non-Small Cell Lung Cancer Cells. PLoS ONE 2016, 11, e0168793. [CrossRef]

225. Cheng, Y.; Diao, D.; Zhang, H.; Guo, Q.; Wu, X.; Song, Y.; Dang, C. High glucose-induced resistance to 5-fluorouracil in pancreatic cancer cells alleviated by 2-deoxy-D-glucose. Biomed. Rep. 2014, 2, 188-192. [CrossRef]

226. Ma, S.; Jia, R.; Li, D.; Shen, B. Targeting Cellular Metabolism Chemosensitizes the Doxorubicin-Resistant Human Breast Adenocarcinoma Cells. BioMed. Res. Int. 2015, 2015, 453986. [CrossRef] [PubMed]

227. Romero-Pozuelo, J.; Figlia, G.; Kaya, O.; Martin-Villalba, A.; Teleman, A.A. Cdk4 and Cdk6 Couple the Cell-Cycle Machinery to Cell Growth via mTORC1. Cell Rep. 2020, 31. [CrossRef] [PubMed]

228. Wang, Q.; Guldner, I.H.; Golomb, S.M.; Sun, L.; Harris, J.A.; Lu, X.; Zhang, S. Single-cell profiling guided combinatorial immunotherapy for fast-evolving CDK4/6 inhibitor-resistant HER2-positive breast cancer. Nat. Commun. 2019, 10, 3817. [CrossRef] [PubMed] 
229. Finn, R.S.; Liu, Y.; Zhu, Z.; Martin, M.; Rugo, H.S.; Diéras, V.; Im, S.-A.; Gelmon, K.A.; Harbeck, N.; Lu, D.R.; et al. Biomarker Analyses of Response to Cyclin-Dependent Kinase 4/6 Inhibition and Endocrine Therapy in Women with Treatment-Naïve Metastatic Breast Cancer. Clin. Cancer Res. 2020, 26, 110. [CrossRef] [PubMed]

230. Silvestri, M.; Cristaudo, A.; Morrone, A.; Messina, C.; Bennardo, L.; Nisticò, S.P.; Mariano, M.; Cameli, N. Emerging Skin Toxicities in Patients with Breast Cancer Treated with New Cyclin-Dependent Kinase 4/6 Inhibitors: A Systematic Review. Drug Saf. 2021. [CrossRef] 